Canadian

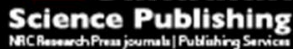

Canadian Geotechnical Journal Revue canadienne de géotechnique

Undrained stiffness anisotropy from Hollow Cylinder experiments on four Eocene-to-Jurassic UK stiff clays

\begin{tabular}{|r|l|}
\hline Journal: & Canadian Geotechnical Journal \\
\hline Manuscript ID & cgj-2015-0320.R1 \\
\hline Manuscript Type: & Article \\
\hline Date Submitted by the Author: & 25-Aug-2016 \\
\hline Complete List of Authors: & $\begin{array}{l}\text { Brosse, Amandine; Geotechnical Consulting Group, } \\
\text { Jardine, Richard; Imperial College London } \\
\text { Nishimura, Satoshi; Hokkaido Univeristy, Faculty of Engineering }\end{array}$ \\
\hline Keyword: & Clays, Laboratory tests, Stiffness, Anisotropy, Stress path \\
\hline & \\
\hline
\end{tabular}

SCHOLARONE ${ }^{\text {IM }}$

Manuscripts 


\section{Undrained stiffness anisotropy from Hollow Cylinder experiments on four Eocene-to- Jurassic UK stiff clays}

Author 1

Brosse, A.,

Formerly: Imperial College London, London, UK

Department of Civil and Environmental Engineering, Skempton Building, South Kensington Campus, Imperial College London, London SW7 2AZ, United Kingdom

Author 2

Jardine, R.J., Imperial College London, London, UK

Department of Civil and Environmental Engineering, Skempton Building, South Kensington Campus, Imperial College London, SW7 2AZ London, United Kingdom

r.jardine@imperial.ac.uk

Author 3

Nishimura, S,

Hokkaido University, Sapporo, Japan

Geotechnical and Material Engineering for Disaster Prevention, Division of Field

Engineering for the Environment, Faculty of Engineering, Hokkaido University

Kita-13 Nishi-8, Kita-ku, Sapporo, Hokkaido, 060-8628, Japan

nishimura@eng.hokudai.ac.jp

\section{Corresponding author:}

Amandine Brosse,

Current affiliation: Geotechnical Consulting Group

52A Cromwell Road, London SW7 5BE, United Kingdom

Tel: +44 (0)20 $75906959 \quad$ Fax: +44 (0)20 75840157

a.brosse@gcg.co.uk 


\section{Abstract}

2 The paper describes the anisotropic undrained stiffness behaviour of four medium-plasticity

3 heavily overconsolidated UK stiff marine clays as revealed through Hollow Cylinder testing.

4 The experiments contributed to two broader studies on stiff-to-hard London, Gault,

5 Kimmeridge, and Oxford clay strata. They involved static and dynamic testing of multiple

6 high quality natural specimens sampled at similar depths from inland sites. This paper

7 explores the directional dependency of the clays' highly non-linear undrained stiffness

8 characteristics. New data-analysis approaches are outlined that allow the stiffnesses

9 associated with one dimensional vertical, horizontal or pure horizontal shear modes to be

10 isolated in complex undrained stress paths. In the presented experiments, loading progressed

11 from in-situ stresses to reach ultimate failure at a range of final major principal stress

12 orientation angles $\alpha$ (defined in the vertical plane) while keeping fixed values of the

13 intermediate principal stress ratio, $b$. The tests reveal strong undrained stiffness anisotropy

14 that can impact significantly on the prediction and understanding of ground deformation

15 patterns in numerous geotechnical engineering applications.

\section{Keywords:}

17 Clays, Laboratory tests, Stiffness, Anisotropy, Stress path 


\section{Introduction}

19 Much of the UK's civil engineering infrastructure and several of its major cities are built on

20 stiff overconsolidated, geologically aged, clays. The clays' highly non-linear stiffness

21 characteristics have an important bearing on geotechnical engineering applications, ranging

22 from tunnels to foundations and deep excavations; see for example Jardine et al. (2005). It is

23 known that the stiff clays have anisotropic micro and macro-structures (see for example

24 Hight et al. 2007 and Hosseini-Kamal et al. 2014) and that stiffness anisotropy can influence

25 ground movement patterns markedly. Finite element simulations by Simpson et al. (1996) and

26 Addenbrook et al. (1997) indicated how accounting for the London clay's marked degree of

27 stiffness anisotropy is critical to making realistic predictions for the settlement troughs

28 developed above tunnels bored in this stratum. While sometimes addressed in research, the

29 influence of anisotropy on non-linear stiffness behaviour is rarely addressed in practical

30 design. Laboratory and field techniques exist to measure anisotropy within the (very small

31 strain) linear elastic range, but a lack of reliable information on stiffness anisotropy over the

32 full non-linear range that affects most engineering analyses is one factor that hinders practical

33 advances in ground movement assessment. Potts and Zdravkovic (2001), for example, noted

34 that a lack of reliable data regarding how the shear modulus $G_{v h}$ degrades with shear strain

35 limits the analysis of ground deformations around tunnels. Due to their typically low

36 permeabilities, the clays' piezometric responses to large scale perturbations often involve

37 only minor pore pressure equalisation during construction; this paper therefore explores the

38 clays' non-linear stiffness anisotropy under undrained conditions. Laboratory experiments

39 with HCAs (Hollow Cylinder Apparatus) are reported on high quality samples of Jurassic to

40 Eocene marine clays that were deposited in broadly similar marine environments. The

41 sampling locations and $\approx 10 \mathrm{~m}$ depths were chosen to reduce potential local effects of tectonic

42 disturbance, post-depositional weathering and glacial or tree action. 
43 The paper combines analysis of HCA experiments conducted by Brosse (2012) on Gault clay 44 sampled near Cambridge, Kimmeridge clay from Steventon (Oxfordshire), and Oxford clay 45 from Elstow (Bedfordshire) along with earlier tests conducted by Nishimura (2006) that 46 contributed to the London clay Heathrow Terminal 5 campaign (Hight et al. 2007). The 47 studies on Gault, Kimmeridge and Oxford clay are detailed in Wilkinson (2011), Brosse 48 (2012) and Hosseini-Kamal (2012). Hosseini-Kamal et al. (2014) present geotechnical 49 profiles for the sites where samples of the latter three strata were taken by careful block and 50 Geobor-S rotary coring techniques.

51 Tables 1 and 2 summarise some key aspects of the properties of the four suites of clay 52 specimens' on which the HCA experiments were conducted, listing their geotechnical 53 descriptions, estimated in-situ effective stresses, meso and micro-structures, index properties, 54 peak triaxial compressive undrained shear strengths (from carefully $\mathrm{K}_{0}$ reconsolidated, $55100 \mathrm{~mm}$ diameters specimens) and residual angles of shearing resistance, as determined in 56 ring shear experiments. Perhaps surprisingly, Hosseini-Kamal et al. (2014) report no clear 57 correlation between the clays' large strain behaviours and their variable ages or burial depths. 58 After removing as far as possible the potential effects of other depositional and post59 depositional factors, they concluded that meso-structure was the most important determinant 60 of the natural clays' large scale yielding behaviour. In this context, the meso-scale falls 61 between the micro- and macro-scales. While the micro-scale is relevant to particle level 62 phenomena and the macro-scale concerns features whose dimensions are comparable to those 63 of built structures (such as faults, extensive joints, etc.), meso-structure features are visible by 64 eye and yet sufficiently small for their effects to be perceived and treated as homogenised 65 characteristics of representative soil elements. Fissures, bedding, laminations and bioturbated 66 features are common examples of meso-structure. The Oxford clay samples had clear bedding 67 features, but no fissures, and developed markedly higher triaxial compression shear strengths 
and post-peak brittleness. The peak triaxial shear strengths of natural samples of the other clays were strongly affected by their greater fissure intensity. All four soils are markedly brittle in shear. Gapsarre et al. (2007a), Hight et al. (2007) and Hosseini-Kamal et al. (2014) show that any tendency to dilate after undergoing 'gross shear yielding' (which we term $\mathrm{Y}_{3}$ to distinguish this feature from earlier small strain yielding phenomena) is truncated by the formation of new discontinuities, the re-mobilisation of any existing discontinuities or fissures, or a combination of the two processes. The test elements are unable to progress towards global critical states and the specimens develop slickensided residual shear mechanisms if the shearing is continued to sufficiently large displacements.

The London clay's drained elastic anisotropy was explored by Gasparre et al. (2007b) in terms of effective stress compliance matrices that were established by:

a) Anh-Minh's (2007) uniaxial drained HCA tests employing high resolution local strain measurements over a wide range of strain and

b) Gasparre's (2005) very small-strain axial and radial drained triaxial probing experiments combined with multi-axis shear wave velocity measurements, following the techniques of Pennington et al. (1997) and Kuwano and Jardine (1998), (2007).

Hosseini-Kamal (2012) applied the same approach, which implicitly assumes strain rate independency, to measure the elastic anisotropic properties of the Gault, Kimmeridge and Oxford clays.

This paper explores the directional dependency of all four clays' non-linear undrained prefailure behaviour. An analysis is made of the HCA experiments that allows the undrained stiffnesses associated with vertical and horizontal compression as well as pure shear deformation modes to be identified from tests in which loading progressed from in-situ stresses to failure at a range of final major principal stress axis orientations (defined as $\alpha$ the 
93 orientation of the $\sigma_{1}$ axis to the vertical), while also maintaining fixed intermediate principal

94 stress conditions.

\section{Apparatus and Procedures}

96 Principles

97 Hight et al. (1983) describe how varying the axial force, torque and inner and outer cell

98 pressures applied to HCA specimens provides control over the vertical, radial, circumferential

99 and torsional shear stresses $\sigma_{z}, \sigma_{r}, \sigma_{\theta}$ and $\tau_{z \theta}$. HCA systems can maintain $\tau_{z r}=\tau_{r \theta}=0$ and

100 provide four degrees of freedom that offer independent control of the $p, q, \alpha$ and $b$ stress

101 parameters defined as:

$102 \quad[1] \quad p=\frac{\left(\sigma_{1}+\sigma_{2}+\sigma_{3}\right)}{3}$

$103[2] \quad q=\sigma_{1}-\sigma_{3}$

$104 \quad[3] \quad \alpha=\frac{1}{2} \tan ^{-1}\left(\frac{2 \tau_{z \theta}}{\sigma_{z}-\sigma_{\theta}}\right)$

$105 \quad[4] \quad b=\frac{\sigma_{2}-\sigma_{3}}{\sigma_{1}-\sigma_{3}}$

$106 \alpha$ is the angle between the major principal stress direction and the vertical. Effects of $\alpha$ on

107 material behaviour are therefore direct indices of anisotropy. The intermediate principal stress

108 ratio $b$ can be varied between 0 and 1 . An additional variable, $\alpha_{\mathrm{d} \sigma}$, is also defined, to indicate

109 the angle between the axis of the major principal stress increment and the vertical (see Figure

1103 ) which, as will be discussed, was used as one of the control variables in the test series.

$111[5] \quad \alpha_{d \sigma}=\frac{1}{2} \tan ^{-1}\left(\frac{2 \mathrm{~d} \tau_{z \theta}}{d \sigma_{z}-d \sigma_{\theta}}\right)$ 


\section{Equipment}

113 The two computer-controlled systems illustrated in Figures 1 and 2 and described by

114 Nishimura et al. (2007), Anh-Minh et al. (2011) and Brosse (2012) were employed in the

115 HCA experiments. Both sets can perform experiments under mixed stress and strain control.

116 The nominal outer diameters, inner diameters and heights of their test specimens were

117 respectively $70 \mathrm{~mm}, 38 \mathrm{~mm}$ and $170 \sim 190 \mathrm{~mm}$ for the Imperial College Resonant Column

118 Hollow Cylinder Apparatus (ICRCHCA) and $100 \mathrm{~mm}, 60 \mathrm{~mm}$ and $200 \mathrm{~mm}$ for the Imperial

119 College Hollow Cylinder Apparatus Mark II (ICHCA II). The ICRCHCA is equipped with a

120 Hardin oscillator that can perform torsional resonant column tests to obtain dynamic $G_{z \theta}$

121 shear moduli. Sample deformation is measured globally, apart from the semi-local (platen-to-

122 platen) torsional rotations, which are sensed with a proximity transducer system. The ICHCA

123 II employed a full suite of high-resolution local transducers. Axial displacements and

124 torsional rotations were measured with enhanced electro-level inclinometers, while changes

125 of the inner and outer radii were measured with a Linear Variable Differential Transformer

126 (LVDT) and a set of three proximity transducers, respectively. From these boundary

127 displacements, the average strains induced in the clay specimens were calculated according to

128 the equations given by Hight et al. (1983).

\section{Specimen preparation}

130 HCA specimens were prepared as described by Nishimura et al. (2007) and Brosse (2012).

131 First cylinders were trimmed to the specified outer dimensions with a wire saw in a rotary

132 soil lathe. The inner cylinder void was then formed by jacketing the sample in an aluminium

133 mould and using a metal working lathe to advance six drill bits of gradually increasing

134 diameters to achieve the desired inner diameter with minimal disturbance. The specimens

135 were carefully installed with (internal and external) latex membranes over systems of surface

136 filter paper drains and set on the sharp edges of shear vanes anchored into the HCAs' sintered 
137 bronze vertical platens. The latter ensured that sufficient traction could be applied during

138 torsional shearing to failure.

139 Test programme

140 The general scheme of the stress paths applied in the undrained HCA tests is illustrated in

141 Figure 3. Both $b$ and $\alpha$ were varied in the London clay tests by Nishimura (2006) and Anh 142 Minh (2007) who investigated a range of depths at one site. Brosse (2012) covered three 143 different sites and clays, but focussed on a narrower depth range and maintained $b=0.5$ in 144 most of her tests. Tables 3 to 6 specify each test's code, sampling depth, reconsolidation 145 effective stresses and shearing effective stress path. The tabulated Oxford, Kimmeridge,

146 Gault and London clay tests, which all involved samples taken from $\approx 10 \mathrm{~m}$ depth and 147 imposed $b=0.5$ during shearing, represent a large proportion of those undertaken by Brosse 148 (2012) and a limited sub-set of the London clay programme. All of the tabulated London clay 149 tests were conducted in the ICRCHCA, while both sets of HCA equipment were deployed in 150 Brosse's experiments. Brosse et al. (2016) demonstrate that the four clays are anisotropic in 151 their undrained shear strength behaviour and Tables 3 to 6 specify the peak undrained shear 152 strengths developed in each test.

\section{Test procedures}

154 All tests started by applying a cell pressure greater than the estimated in-situ mean effective 155 stress to induce a positive pore pressure once full contact was made with the platens. The 156 system was saturated by back pressure to acceptable undrained pore pressure response $B$ 157 ratios above 0.9 in most of the tests. While all the specimens had been sampled from below 158 the water table, where they had experienced high degrees of saturation, their relatively high 159 effective bulk moduli limited their theoretical $B$ values to $0.95-0.97$, even when perfectly 160 saturated. Careful handling, line flushing, thorough saturation of the porous discs and an 161 elevated back pressure helped to maximise the set-up stage B values. Maintaining the high 
162 back pressure over the subsequent re-consolidation and creep stages should have led to still 163 higher final, pre-shearing, $B$ values.

164 All specimens were reconsolidated to anisotropic effective stress states reflecting the 165 estimated in-situ values. The suction measurements on multiple triaxial and HCA samples 166 presented in Table 7 allowed $\mathrm{K}_{0}$ values $(\mathrm{all}>1)$ to be estimated for each site and depth, after 167 making an allowance for deviator stress release (using the dq/dp' slopes given in Table 7) and 168 carefully establishing the in-situ vertical effective stress. The resulting range of $\mathrm{K}_{0}$ values are 169 all close to the passive limit, as were other estimates derived from Mayne and Kulhawy's 170 (1982) equations and in-situ measurements made with a Marchetti dilatometer in 171 Kimmeridge clay and a self-boring pressuremeter in Oxford clay. Isotropic reconsolidation 172 was conducted first to reach the desired $p^{\prime}$ values and then $\left(\sigma_{z}-\sigma_{\theta}\right) / 2$ was reduced, keeping 173 constant $p^{\prime}$, to reach the final effective stress points. The axial straining experienced during anisotropic reconsolidation was restricted to a maximum of $0.5 \%$ to avoid any premature 175 destructuration of the high quality samples. The first clay tested was Oxford clay and it was 176 found that the estimated $\mathrm{K}_{0}$ values (3.2) could not be reached without over-straining the 177 specimens during re-consolidation. Trial tests showed that it was necessary to adopt a lower $178 \mathrm{~K}(1.8)$ and therefore a higher vertical stress (see Tables 1 and 3) than had been originally 179 estimated. When moving on to test the Gault and Kimmeridge clays, it was decided to 180 maintain the same $\mathrm{K}_{0}=1.8$ for compatibility, noting that this value fell towards the lower end 181 of the estimated $\mathrm{K}_{0}$ range.

182 Stiffness measurements can be severely compromised by any residual creep straining that 183 may apply prior to shearing; see Jardine (1985) or Gasparre et al. (2014). Sufficient pause 184 times were therefore imposed after the end of all consolidation stages for creep rates to 185 stabilise before commencing undrained shearing. Several days were required for the 186 volumetric and deviatoric strain rates to fall below the adopted $0.002 \%$ per hour criterion 
187 recommended by Jardine (1985). This rate is in order of $1 / 100$ of the subsequent strain rate

188 (0.15\% per hour, as described later). This condition is similar to the limit Jardine (1985)

189 recommended and Clayton and Heymann's (2001) found necessary to ensure that consistent

190 Young's moduli are measured in triaxial compression and extension over the initial (pre- $Y_{1}$

191 yielding) elastic range. Allowing for further creep stabilisation may also affect the later non-

192 linear stiffness behaviour by allowing the kinematic $\left(\mathrm{Y}_{1}\right.$ and $\left.\mathrm{Y}_{2}\right)$ 'small-strain' yield surfaces

193 identified by Jardine (1992) to adjust. However, waiting for the creep rates to reduce to much

194 slower rates would have required the tests to be extended to prohibitively long durations

195 (possibly many months), an option that could not be explored practically. The shearing stages

196 involved a first step of changing $b$ from its initial value of unity (which applies with $K_{0}>1$ )

197 to a value of 0.5 under undrained conditions, while keeping $p, q$ and $\alpha$ constant. After

198 allowing 12 hours for minor additional creep, further undrained shearing was initiated with

199 constant $p, b$ and $\alpha_{d \sigma}$ values. It follows that $\alpha$ varied during undrained shearing except in the

$200 \alpha_{d \sigma}=90^{\circ}$ tests. The $\alpha_{d \sigma}$ paths were set so that failure (taken as reaching peak $q$ in this case)

201 would develop at target $\alpha$ values of $0^{\circ}, 23^{\circ}, 45^{\circ}, 67^{\circ}$ and $90^{\circ}$ respectively, which are denoted

202 as $\alpha_{f}$. Tables 3 to 6 present the chosen values of $\alpha_{d \sigma}$ with the corresponding actual value of $\alpha_{f}$.

203 The shearing stages were conducted under a mixed stress and strain control arrangement, set

204 to give an average deviatoric strain rate of $0.15 \%$ per hour.

205 Small-strain non-destructive resonant column tests were conducted during ICRCHCA tests to

206 monitor the variation of the elastic $G_{z \theta}$ during reconsolidation and shearing. Brosse (2012)

207 reports on the Resonant Column apparatus, test procedures, calibrations and test 208 interpretation.

\section{Stress and strain measurements}

210 The accurate measurement, from the very early stages of shearing up to failure, of the four 211 dimensional stress and strain states developed in HCA tests poses considerable technical 
212 difficulties. The HCA cells illustrated in Figures 1 and 2 were set in a tightly temperature 213 regulated laboratory. Stable, 16 bit resolution auto-ranging Analogue to Digital converters 214 were employed to track the stress and strain measurements. Both HCA systems employed 215 inner and outer cell pressure measurements as well as purpose-designed dual axis, pressure 216 compensated internal load cells that measured the axial force and torque applied to the 217 samples. These bi-axial cells were carefully calibrated for both direct and cross-sensitivity 218 under the load paths applied employed for testing. As described above, for most of the tests, 219 strain measurements were realised using a mix of global and semi-local (platen-to-platen) in 220 the ICRCHCA except for the Kimmeridge clay series where local instrumentation was employed in the ICHCA II.

222 A key factor when attempting to measure soil stiffness at small strain is the limiting stable 223 resolution of the stress and strain sensing systems; see for example Jardine et al. (1984) or 224 Gasparre et al. (2014). Table 8 lists the theoretical strain resolution limits based on the 225 instruments fitted to each apparatus. Brosse (2012) noted that the HCA instruments' scatter 226 limited the ability to define stiffness at small strains. As described later, further filtering and 227 post-processing has been performed to enhance the clarity of the traces recorded at very small 228 strains.

229 It is well known that external strain measurements can be unrepresentative over the early 230 stages of soil shearing tests due to apparatus compliance, potentially eccentric loading and 231 imperfect platen-to-specimen contact. Radial strains deduced from volume strains can also be 232 affected by straining non-uniformity and membrane penetration. Ideally, triaxial and HCA 233 strains should be measured with high resolution local strain sensors, such as those described 234 by Burland and Symes (1982) or Tatsuoka et al. (1997). However, such systems can be 235 difficult to apply in HCA tests on natural stiff clays that are subjected to high cell pressures 236 over extended durations and taken ultimately to large strain failure. 
237 Local strain instruments were deployed in the ICHCA II tests and compliance effects were

238 alleviated with the ICRCHCA by (i) employing platen-to-platen shear strain measurements

239 and (ii) correcting the external axial strain measurements for the system compliance, which

240 was calibrated carefully; Brosse (2012). Membrane penetration was not significant with the

241 fine grained clays. Checks were made of any potential remaining strain measurement errors

242 by comparing equivalent measurements from: the two independent HCA systems; fully

243 instrumented triaxial tests; and by contrasting static torsional shear measurements with output

244 from fully independent resonant column and dynamic bender element measurements. The

245 degree of agreement seen in such checks was generally encouraging. As discussed later, the

246 resonant column measurements tended to indicate marginally higher shear moduli than other

247 static and dynamic $G_{v h}$ tests. Recognizing that static stiffnesses may not have been defined as

248 accurately as desired over the very small strain linear range, parallel triaxial tests were

249 undertaken with very high resolution local strain sensors; see Gasparre et al. (2007b) and

250 Hosseini-Kamal (2012). Gasparre et al. (2007b) tracked the details of how the $Y_{1}$ and $Y_{2}$

251 kinematic yield surfaces manifested by the London clay evolved with depth and effective

252 stress state, while Hosseini-Kamal (2012) reported on the kinematic yielding features

253 exhibited by the three other stiff clays. However, as noted in the introduction, this paper

254 focuses principally on the evolution of the stiffness anisotropy manifested on various loading

255 paths that start from in-situ $\mathrm{K}_{0}$ conditions, covering the extended non-linear range that

256 controls ground movements and soil-structure interaction in the field; Addenbrooke et al.

257 (1997).

258 Characterising the stress-strain response

259 Characterising stiffness from very small strains to failure also poses theoretical difficulties.

260 Jardine (1992), (2014) emphasises that behaviour can only be considered elastic within a very

261 small area of the stress space available to soils that is limited by a kinematic hardening $\left(\mathrm{Y}_{1}\right)$ 
262 true yield surface. The latter is dragged with the current effective stress point, growing and 263 shrinking with $p^{\prime}$ and changing in shape with proximity to the outer $\mathrm{Y}_{3}$ surface, which 264 corresponds to the yield surface recognised in classical critical state soil mechanics.

265 Behaviour within the true $\mathrm{Y}_{1}$ yield surface has been found to be broadly cross anisotropic in 266 vertically sedimented $\mathrm{K}_{0}$ consolidated soils; Jardine et al. (2004), Nishimura (2014a). The 267 horizontal Young's moduli can greatly exceed the vertical values in high OCR clays; 268 Gasparre et al. (2007b), Hosseini-Kamal (2012).

269 Plastic straining commences once the $\mathrm{Y}_{1}$ surface is engaged and becomes progressively more 270 important as straining continues along any monotonic path. An intermediate kinematic $\mathrm{Y}_{2}$ 271 surface was identified for London clay by Gasparre et al. (2007b) that marks: (i) potential 272 changes in strain increment directions, (ii) the onset of marked strain-rate or time dependency 273 and (iii) a threshold condition in cyclic tests (as noted by Vucetic 1994) beyond which 274 permanent strains (or $p^{\prime}$ reductions in constant volume tests) accumulate significantly. The 275 initial proximity to the $Y_{2}$ surface affects the extent of the $Y_{1}$ region. In the same way, the 276 location of the anisotropic $\mathrm{Y}_{3}$ surface constrains the non-linear stiffness response. Any 277 attempt to treat the non-linear stiffness behaviour within the framework of elasticity is 278 constrained by these fundamental limitations and by possible interactions between the 279 different modes of deformation imposed by multi-axial HCA experiments.

280 Nevertheless, the cross-anisotropic elastic framework provides a simple and clear way of 281 expressing potential stiffness anisotropy and the practical impact of anisotropic pre-failure 282 behaviour can be addressed analytically by incorporating a non-linear elastic approach into 283 conventional elastic-plastic models (Addenbrooke et al. 1997). Brosse (2012) retained this 284 framework and the constitutive Equation 6 given below for her test interpretation, while also 285 highlighting aspects of her experiments that deviated from this simple theory. In Equation 6, 286 E, G and $\mu$ are respectively the Young's moduli, the shear moduli and the Poisson's ratio and 
287 can be either effective or undrained parameters depending on the set of stresses used in

288 Equation 6 (effective or total stresses respectively). The subscripts $\mathrm{v}$ and $\mathrm{h}$ represent the 289 vertical and horizontal directions respectively. In the present study, it is assumed that the 290 horizontal directions $\mathrm{x}$ and $\mathrm{y}$ can be interchanged with the radial and circumferential 291 directions due to the axis symmetry of the model. As demonstrated by Love (1927), the 292 relationships given in Equations 7 and 8 exist between cross-anisotropic material parameters 293 and consequently only 5 independent parameters are required to fully describe the soil 294 behaviour in the drained case.

295

$$
\left\{\begin{array}{c}
\delta \varepsilon_{r} \\
\delta \varepsilon_{\theta} \\
\delta \varepsilon_{z} \\
\delta \gamma_{\theta z} \\
\delta \gamma_{z r} \\
\delta \gamma_{r \theta}
\end{array}\right\}=\left[\begin{array}{cccccc}
\frac{1}{E_{h}} & \frac{-\mu_{h h}}{E_{h}} & \frac{-\mu_{v h}}{E_{v}} & 0 & 0 & 0 \\
\frac{-\mu_{h h}}{E_{h}} & \frac{1}{E_{h}} & \frac{-\mu_{v h}}{E_{v}} & 0 & 0 & 0 \\
\frac{-\mu_{h v}}{E_{h}} & \frac{-\mu_{h v}}{E_{h}} & \frac{1}{E_{v}} & 0 & 0 & 0 \\
0 & 0 & 0 & \frac{1}{G_{h v}} & 0 & 0 \\
0 & 0 & 0 & 0 & \frac{1}{G_{v h}} & 0 \\
0 & 0 & 0 & 0 & 0 & \frac{2\left(1+\mu_{h h}\right.}{E_{h}}
\end{array}\right]\left\{\begin{array}{l}
\delta \sigma_{r} \\
\delta \sigma_{\theta} \\
\delta \sigma_{z} \\
\delta \tau_{\theta z} \\
\delta \tau_{z r} \\
\delta \tau_{r \theta}
\end{array}\right\}
$$

$296 \quad[7] \quad \frac{\mu_{v h}}{E_{v}}=\frac{\mu_{h v}}{E_{h}}$

297

[8] $\quad G_{h h}=\frac{E_{h}}{2\left(1+\mu_{h h}\right)}$

298 Up to four sets of independent stress/strain relationships can be measured in HCA tests.

299 Resolving the material parameters from such measurements usually requires that specific 300 stress paths are followed to obtain a given parameter. For example, stress probe tests often 301 measure how the four strain components respond to changes applied to just one stress 302 component at a time. However, in the undrained case, the soil deforms at constant volume 
and the additional relationships given in Equations 9 and 10 apply (Gibson 1974). The

304 number of independent parameters required to describe the constitutive relationship therefore

305 reduces to three. The superscript $U$ designates undrained in the following parameter sets.

$306 \quad[9] \quad \mu_{v h}^{U}=\frac{1}{2}$

307

$[10] \quad \mu_{h h}^{U}=1-\mu_{h v}^{U}=1-\frac{1}{2} \frac{E_{h}^{U}}{E_{v}^{U}}$

308 Combining Equations 6, 9 and 10 and moving to axially symmetric coordinates gives the

309 relationships in Equations 11 to 14. Applying these expressions to the present undrained HCA

310 tests made it possible to resolve the variation of the secant values of the three independents

311 parameters $\mathrm{E}_{\mathrm{v}}{ }^{\mathrm{U}}, \mathrm{E}_{\mathrm{h}} \mathrm{U}$ and $\mathrm{G}_{\mathrm{vh}}$ from the stresses imposed and the strains measured.

$[11] \quad E_{v}^{U}=\frac{2 \delta \sigma_{z}-\delta \sigma_{r}-\delta \sigma_{\theta}}{2 \delta \varepsilon_{z}}$

$[12] \quad E_{h r}^{U}=\frac{\delta \sigma_{r}\left(\delta \sigma_{r}-2 \delta \sigma_{z}\right)-\delta \sigma_{\theta}\left(\delta \sigma_{\theta}-2 \delta \sigma_{z}\right)}{\delta \varepsilon_{r}\left(\delta \sigma_{r}+\delta \sigma_{\theta}-2 \delta \sigma_{z}\right)+\delta \varepsilon_{z}\left(\delta \sigma_{\theta}-\delta \sigma_{z}\right)}$

314

[13] $\quad E_{h \theta}^{U}=\frac{\delta \sigma_{r}\left(\delta \sigma_{r}-2 \delta \sigma_{z}\right)-\delta \sigma_{\theta}\left(\delta \sigma_{\theta}-2 \delta \sigma_{z}\right)}{\delta \varepsilon_{\theta}\left(\delta \sigma_{r}+\delta \sigma_{\theta}-2 \delta \sigma_{z}\right)+\delta \varepsilon_{z}\left(\delta \sigma_{r}-\delta \sigma_{z}\right)}$

$[14] \quad G_{v h}=\frac{\delta \tau_{z \theta}}{\delta \gamma_{z \theta}}$

316 For transversely isotropic media, the horizontal Young's moduli deduced from radial strain

317 measurements $\left(\mathrm{E}_{\mathrm{hr}}^{\mathrm{U}}\right)$ should be equal to those deduced from circumferential strain

318 measurements $\left(\mathrm{E}_{\mathrm{h} \theta}^{\mathrm{U}}\right)$ as the properties are considered isotropic within the horizontal plane. In

319 the present paper, the two values obtained independently from Equations 12 and 13 were

320 averaged to provide the best estimates for $\mathrm{E}_{\mathrm{h}}^{\mathrm{U}}$. The $\mathrm{E}_{\mathrm{v}} \mathrm{U}$ and $\mathrm{E}_{\mathrm{h}} \mathrm{U}$ parameters could be resolved

321 in all the tests, while $\mathrm{G}_{\mathrm{vh}}$ could only be resolved in those involving continuous rotations of 
322 the principal stress axes, as in the $\alpha_{d \sigma}=23^{\circ}, 45^{\circ}$ and $67^{\circ}$ experiments. Whenever possible,

323 independent measurements of $\mathrm{G}_{\mathrm{vh}}$ were also made during shearing with the ICRCHCA's built

324 in resonant column system.

\section{Experimental outcomes}

\section{Data processing}

327 The main focus of this paper is on the anisotropic undrained stiffness characteristics observed

328 in the HCA experiments conducted on the four clays. Figures $4 \mathrm{a}$ and $4 \mathrm{~b}$ present one typical

329 test that involved principal stress rotation to $\alpha_{f}=23^{\circ}$ with $b=0.5$ on Oxford clay, showing

330 how the key stress and strain components varied over its full shearing stage. Applying

331 Equations 11 to 13 gave the two undrained overall (elastic-plastic) secant Young's moduli

332 trends with strain displayed in Figure 5. The results indicate an anisotropic response, but the

333 degree of instrument scatter experienced at very small strains led to uncertainty about the,

334 presumably linear, initial stiffness response. The impact was greatest for the horizontal

335 undrained Young's moduli, because their derivation depends on two strain variables while the

$336 \quad \mathrm{E}_{\mathrm{v}} \mathrm{U}^{\mathrm{U}}$ and $\mathrm{G}_{\mathrm{vh}}$ stiffness expressions only rely on one strain component each.

337 Further post processing of the raw data has been carried out that involved:

338 - Least square linear regressions over the strain range up $0.005 \%$ in order to determine

339 best fitting initial $\mathrm{E}_{\mathrm{v} 0} \mathrm{U}, \mathrm{E}_{\mathrm{h} 0} \mathrm{U}$ and $\mathrm{G}_{\mathrm{vh} 0}$ values. These moduli do not necessarily

340 coincide with true elastic values but define the parameters up to the lowest strain limit

341 at which stiffness could be defined meaningfully given the available strain

342 measurement resolution and signal scatter. It is possible that the stiff clays' engaged

343 their $\mathrm{Y}_{1}$ limits at smaller strains.

344 - A Savitzky-Golay filter was applied over the next decadal strain range (from $0.005 \%$

345 to $0.05 \%$ ) to the $\varepsilon_{r}, \varepsilon_{\theta}, \sigma_{z}, \sigma_{r}$ and $\sigma_{\theta}$ data sets. The filter performed a piece wise fitting 
of polynomial functions by least square regression; order 2 functions were adopted in this study. This approach, among those attempted, led to the most consistent smoothing and clearest presentation of the data. It should be noted, however, that

Although laborious, the reprocessing led to the clearer non-linear stiffness trends exhibited as

353 black continuous curves in Figure 5, where the initial linear regression best fit stiffness values

354 for test OA2305 are also shown.

355 A key consideration when reporting the non-linear anisotropy is the choice of strain 356 parameter with which each elastic-plastic stiffness trend should be correlated. In conventional 357 triaxial tests, vertical stiffness degradation is usually correlated with increasing axial strain $\varepsilon_{z}$, 358 or shear strain invariant $\varepsilon_{s}=2\left(\varepsilon_{1}-\varepsilon_{3}\right) / 3$, which equals $\varepsilon_{z}$ in undrained tests. General invariant 359 measures of deviatoric strain are often employed to define octahedral shear stiffness 360 variations in numerical analysis; see for example Potts and Zdravkovic (1999), (2001). It is

361 less clear how anisotropic non-linear behaviour should be treated and Brosse (2012) assessed

362 several options including: (i) plotting all stiffnesses against octahedral shear strain, (ii)

363 relating a given stiffness with the "predominant" influential strain (for example $\mathrm{E}_{\mathrm{v}}{ }^{\mathrm{U}}$ with $\varepsilon_{\mathrm{z}}$ ),

364 and (iii) other combinations. No single choice led to an ideal synthesis of the recorded data,

365 but the clearest trends were found by correlating the secant vertical, horizontal and torsional

366 shear stiffnesses with the $\varepsilon_{z},\left(\varepsilon_{r}+\varepsilon_{\theta}\right) / 2$ and $\gamma_{z \theta}$ strains respectively (Option (ii) above).

367 Summary plots with these axes are presented in Figures 6 to 17 showing the secant stiffness

368 trends from undrained HCA tests that brought the four clays to failure (starting from

369 nominally $\mathrm{K}_{0}$ initial conditions) at final $\sigma_{l}$ inclinations $\left(\alpha_{f}\right)$ from the vertical between $0^{\circ}$ to

$37090^{\circ}$ while maintaining $b=0.5$. Also shown are elastic $\mathrm{G}_{\mathrm{vh}}$ moduli determined from concurrent 
371 resonant column tests, as interpreted using the Ashmawy and Drnevich (1994) three degree of

372 freedom model, accounting for apparatus compliance.

\section{Young's moduli degradation}

374 Figures 6 to 13 present $\mathrm{E}_{\mathrm{v}}{ }^{\mathrm{U}}$ and $\mathrm{E}_{\mathrm{h}}{ }^{\mathrm{U}}$ degradation traces for each of the twenty-five constant $375 \alpha_{d \sigma}$ HCA tests. The Kimmeridge series is the only set in which strains were measured locally.

376 Of these, KA0005 presents a softer $\mathrm{E}_{\mathrm{v}}^{\mathrm{U}}$ trend than its companions, probably because of a 377 malfunction in one of its axial strain sensors. The resulting reliance on just one electro-level 378 device rendered the stiffness calculations liable to significant potential errors in the event of 379 any tilting or non-axial misalignment.

380 Truly elastic transversely isotropic materials should develop stiffness $\left(\mathrm{E}_{\mathrm{v}}^{\mathrm{U}}, \mathrm{E}_{\mathrm{h}}^{\mathrm{U}}, \mathrm{G}_{\mathrm{vh}}\right)$ 381 degradation curves that are independent of the shearing path $\left(\alpha_{d \sigma}\right)$ and HCA test curves that 382 lie in a narrow band for each clay. However, the experimental Young's modulus curves vary 383 with $\alpha_{d \sigma}$ and the horizontal stiffness trends show a wider spread than the vertical equivalents. $384 \mathrm{E}_{\mathrm{h}}^{\mathrm{U}}$ depends on two strain measurements ( $\varepsilon_{z}$ and $\varepsilon_{r}$ or $\varepsilon_{\theta}$, see Equations 12 and 13) and this 385 introduces greater scatter at small strains than the single measurement required for $\mathrm{E}_{\mathrm{v}} \mathrm{U}$. The 386 deviation from elastic theory reflects the in-elastic and plastic nature of the straining 387 developed once the very small strains required to engage the $\mathrm{Y}_{1}$ surface have been exceeded. 388 While unique elastic $E_{v \max }, E_{h \max }$ and $G_{v h m a x}$ may well apply within $Y_{1}$ for each clay, these 389 values could not be resolved statically in most of the HCA tests described herein.

390 Close inspection shows no overall systematic trend of variation with $\alpha_{d \sigma}$ in the Young's 391 moduli stiffness curves. The only exceptions are the $\alpha_{f}=67^{\circ}$ experiments, whose $\mathrm{E}_{\mathrm{h}}^{\mathrm{U}}$ and $\mathrm{E}_{\mathrm{v}}^{\mathrm{U}}$ 392 curves consistently fall below their companions. Brosse (2012) reviewed possible reasons for 393 this outcome. Firstly, while random heterogeneity is always present within natural samples, it 394 is highly unlikely to be the cause of such a consistent pattern in the four soils. In the same 395 way, it is true that the $\alpha_{f}=67^{\circ}$ experiments all predominantly involved torsion and only 
396

397

398

399

400

401

402

minor axial and horizontal straining, creating scope for the calculated moduli to be affected significantly by even minor cross sensitivity between the torsional and other strain components. However, the same features apply to the $\alpha_{f}=45^{\circ}$, which do not present similarly anomalous $\mathrm{E}_{\mathrm{h}}^{\mathrm{U}}$ and $\mathrm{E}_{\mathrm{v}}^{\mathrm{U}}$ stiffness degradation curves. Brosse (2012) concluded that the 'unusually soft' $\alpha_{f}=67^{\circ}$ trends most likely result from the relationship between the in-situ stress state, the stress path direction and the clays' anisotropic $\mathrm{Y}_{3}$ yield surfaces. The reconsolidation paths took the effective stress points relatively close to passive failure. As noted earlier and shown in Tables 3 to 6 , the clays' have anisotropic undrained strengths $S_{u}$ that often present relatively low $\mathrm{S}_{\mathrm{u}}$ in tests that apply torsion. Figure 18 presents the Oxford clay tests' shear strength envelope in $\tau_{\mathrm{z} \theta}-\left(\sigma_{\mathrm{z}}-\sigma_{\theta}\right) / 2$ space. Shearing to $\alpha_{f}=67^{\circ}$ involved applying a combination of extension and torsional straining. As illustrated in Figure 18, the combination of (i) the shape of the $\mathrm{Y}_{3}$ yield surfaces and (ii) the starting in-situ stress state led to the $\alpha_{f}=67^{\circ}$ stress path offering the shortest and most direct route towards the failure envelope, explaining the faster development of strain, as shown by the strain contours in Figure 18. Brosse (2012) concluded that combining these factors led to the clays' $\mathrm{Y}_{1}, \mathrm{Y}_{2}$ and $\mathrm{Y}_{3}$ surfaces being engaged at particularly early stages in all $\alpha_{f}=67^{\circ}$ tests.

Non-linear analyses of practical boundary value problems are often modelled with parameters calibrated against stiffness degradation curves from triaxial compression tests; Jardine et al. (2005). Comparison of the $\mathrm{HCA}_{\mathrm{v}}^{\mathrm{U}}$ results with curves from triaxial compression tests starting from similar stress levels indicates that the latter fall towards the upper range of the HCA tests; Brosse (2012). Analyses using isotropic non-linearity calibrated against triaxial compression curves may then over-estimate the $\mathrm{E}_{\mathrm{v}}{ }^{\mathrm{U}}$ stiffness response, while underestimating $\mathrm{E}_{\mathrm{h}}^{\mathrm{U}}$ values over the operational strain range of even routine geotechnical engineering applications that involve vertical and lateral loading as well as principal stress axis rotation, such as embankments, footings or excavations; Jardine (1994). 
Stiffness anisotropy

422 Comparison the $\mathrm{E}_{\mathrm{v}}^{\mathrm{U}}$ and $\mathrm{E}_{\mathrm{h}}{ }^{\mathrm{U}}$ degradation curves reveals a hierarchy of stiffness anisotropy 423 among the four heavily over-consolidated stiff clays. The degree of anisotropy can be 424 quantified by the evolution of the $\mathrm{E}_{\mathrm{h}} \mathrm{U} / \mathrm{E}_{\mathrm{v}}^{\mathrm{U}}$ ratio with strain as presented in Figure 19 for $\alpha_{f}=$ $4250^{\circ}, 45^{\circ}$ and $90^{\circ}\left(23^{\circ}\right.$ and $67^{\circ}$ were omitted as their curves are similar to the $0^{\circ}$ and $90^{\circ}$ 426 respectively). The ratio between the two Young's moduli remains relatively stable up to at 427 least $0.01 \%$ strain and, while varying at larger strain, it remains above unity up to $0.1 \%$ strain 428 (except for Kimmeridge clay). As expected for these heavily over-consolidated deposits, all 429 four clays are stiffer in the horizontal direction than in the vertical. The largest variations in $430 \mathrm{E}_{\mathrm{h}} \mathrm{U} / \mathrm{E}_{\mathrm{v}}^{\mathrm{U}}$ are observed in $\alpha_{f}=45^{\circ}$ tests. Oxford clay presents the highest ratio (2-3) 431 independently of the direction of shearing, while Kimmeridge shows the lowest (1-1.5) and 432 the Gault and London clays exhibit intermediate degrees of stiffness anisotropy. The linearly 433 fitted, initial average stiffness values for each soil (excluding the anomalous $\alpha_{f}=67^{\circ}$ tests) 434 given in Table 9 reflect the same hierarchy of stiffness anisotropy.

435 The exact reasons for the observed hierarchy of stiffness anisotropy are not fully clear. The 436 clays' particle-scale properties and micro-fabrics are likely to be influential; see Nishimura 437 (2014a). However, meso-structure or fissuring does not appear to affect stiffness greatly, 438 provided the test specimens are under sufficient confinement to keep any discontinuities fully 439 closed; see Costa-Filho (1980) or Gasparre et al. (2007b). In the same way, stress-induced 440 anisotropy does not appear to have a major influence under the conditions investigated, as the 441 geologically aged clays' stiffnesses are relatively insensitive to pre- $Y_{3}$ effective stress 442 changes; Hosseini-Kamal (2012). While all four clays were tested after consolidation to 443 similar $\mathrm{K}_{0} \mathrm{~s}$ and effective stress states, they manifested a wide range of degrees of stiffness 444 anisotropy. 
445 It is noteworthy that this hierarchy appears to correlate well with the strength anisotropy 446 observed in terms of peak $\phi^{\prime}$ (or $t / s^{\prime}$ ratio) with Oxford clay presenting the highest $447\left(t / s_{\text {max }}^{\prime}\right) /\left(t / s_{\text {min }}^{\prime},\right)$ ratio at peak, Kimmeridge the lowest and Gault and London clays in between 448 values.

\section{Torsional shear stiffness degradation curves}

450 Secant torsional shear stiffness traces of $\mathrm{G}_{\mathrm{z} \theta}$ (i.e. $\mathrm{G}_{\mathrm{vh}}$ ) with $\gamma_{z \theta}$ are given in Figures 14 to 17 451 from the three torsional tests in the 'constant $\alpha_{d \sigma}-b=0.5$ ' series on each clay. Also shown 452 are the curves from HCA simple shear tests that started from the same estimated in-situ 453 stresses. The resulting four groups of $\mathrm{G}_{z \theta}-\gamma_{z \theta}$ curves fall in a narrow band for each soil 454 demonstrating a convincing correlation that is not influenced systematically by the other 455 strain components or the direction of shearing $\alpha_{d \sigma}$. Comparing the static $\mathrm{G}_{\mathrm{vh} 0}$ values with the $456 \mathrm{E}_{\mathrm{v} 0} \mathrm{U}$ values in Table 9 shows that $\mathrm{G}_{\mathrm{vh} 0} / \mathrm{E}_{\mathrm{v} 0} \mathrm{U}$ falls close to the $1 / 3$ ratio expected for an 457 isotropic soil. Nishimura (2014b) found the same result in tests on six sedimentary clays, with 458 apparently little sensitivity to applied stress states.

459 The agreement between tests' $\mathrm{G}_{\mathrm{z \theta}}$ curves is encouraging. The ICRCHCA tests' all relied on 460 platen-to-platen $\gamma_{z \theta}$ measurements. The Kimmeridge clay's ICHCA II trends, which were 461 derived from local shear strain measurements, agree closely with that from the ICRCHCA 462 simple shear test, verifying that platen-to-platen $\gamma_{z \theta}$ measurements match the local shear strain 463 response. Also presented in Figures 14 to 17 are the dynamic resonant column system $\mathrm{G}_{\mathrm{vhmax}}$ 464 measurements, which involve far smaller strain perturbations than the static torsional shear 465 tests and relatively fast $(\approx 150 \mathrm{~Hz})$ cycling. If the material behaviour was rate independent and 466 elastic then the $R C \mathrm{G}_{\mathrm{vhmax}}$ measurements and static $\mathrm{G}_{\mathrm{vh} 0}$ values should converge. However, 467 the latter are lower, typically by around $15 \%$ to $25 \%$, than the former. Possible explanations 468 include: the static tests underestimating true elastic values that may apply at strains too small 
469 to resolve reliably in the HCAs, rate and frequency effects, or imperfections in RC

470 interpretation theory. For comparison, bender elements tests carried out on triaxial samples

471 tended to give lower values than the RC, except for Oxford clay where they were about $20 \%$

472 higher.

473 The $\mathrm{G}_{\mathrm{vhmax}}$ determinations made at various stages of static shearing indicate a gradual and

474 limited reduction as shearing progresses that apparently reverses after about $1 \%$ torsional 475 shear strain. However, shear bifurcations usually started to appear at such strains that 476 invalidate the assumption of sample continuity on which the resonant column test 477 interpretation relies.

\section{Summary and conclusions}

479 This paper has outlined how anisotropic non-linear stiffness characteristics were investigated 480 and evaluated from suites of 25 undrained HCA tests on high quality natural samples of four 481 geologically old UK stiff clays. The key conclusions are:

482 1. Manipulation of the theory for transversely isotropic elastic media led to simple 483 expressions for the $\mathrm{E}_{\mathrm{v}}^{\mathrm{U}}, \mathrm{E}_{\mathrm{h}}^{\mathrm{U}}$ and $\mathrm{G}_{\mathrm{vh}}$ moduli that could be evaluated from the main run

2. The clays all showed steep falls in secant stiffness with strain. The non-linearity of their responses was characterised by correlating the observed degradation of $\mathrm{E}_{\mathrm{v}}^{\mathrm{U}}, \mathrm{E}_{\mathrm{h}}^{\mathrm{U}}$ and $\mathrm{G}_{\mathrm{vh}}$ with the measured $\varepsilon_{z},\left(\varepsilon_{r}+\varepsilon_{\theta}\right) / 2$ and $\gamma_{z \theta}$ strains respectively.

4903 . The initial segments of the stiffness strain curves were affected by significant scatter. The small-strain stiffness measurements were enhanced by applying linear stressstrain fitting up to $0.005 \%$ strain and then further filtering including polynomial fitting 
instruments deployed to resolve the initial (within $\mathrm{Y}_{1}$ ) linear stiffnesses exactly, but the processing clarified the vertical and torsional shear data sets considerably. The small-strain horizontal stiffnesses remained subject to greater spreading because they relied on two independent sets of scattering strain measurements.

4. The resulting trends indicated a hierarchy of non-linear stiffness anisotropy in the four clays, which was generally independent of the $\sigma_{l}$ orientations followed in each test. Oxford clay presents the highest $\mathrm{E}_{\mathrm{h}} \mathrm{U}_{\mathrm{V}} \mathrm{E}_{\mathrm{v}} \mathrm{U}$ ratio and Kimmeridge clay the lowest. Gault and London clays exhibit intermediate degrees of stiffness anisotropy.

5. The secant stiffness $\mathrm{E}_{\mathrm{h}}{ }^{\mathrm{U}}$ and $\mathrm{E}_{\mathrm{v}}^{\mathrm{U}}$ degradation curves varied with $\alpha_{d \sigma}$ and so deviated from the behaviour expected for ideal non-linear cross-anisotropic materials, reflecting the plastic nature of the straining developed once the $Y_{1}$ and $Y_{2}$ kinematic yield surfaces have been engaged. There was no apparent overall systematic trend of variation with shearing direction, except for the $\alpha_{f}=67^{\circ}$ direction experiments, which

5116 6. The torsional shear stiffness data presented the least scatter and the clearest trends, 512 indicating $G_{z \theta}-\gamma_{z \theta}$ trends that were practically independent of the shearing stress 513 paths. However, the interpreted initial static (linear) values of $\mathrm{G}_{\mathrm{z \theta}}$ typically fell 15 to $51425 \%$ below the 'elastic' values found at much smaller strains in concurrent high 515 frequency resonant column tests. This may be due to: a possibly very limited elastic 516 strain range, frequency dependency in the four clays tested or imperfections in RC 517 interpretation procedures. 
518 7. The strong non-linearity and anisotropy revealed by the HCA tests has important

519 implications for engineering practice in the strata studied; affecting ground movement

520 predictions and soil-structure interaction responses in applications ranging from

521 tunnelling to the settlements and group action of friction piles; Jardine et al. (2005).

522 The above experimental and interpretative approaches may be refined if higher resolution

523 static strain measurement systems can be deployed to bring still greater convergence between

524 static and dynamic measurements and improve stiffness definition (especially for $\mathrm{E}_{\mathrm{h}}{ }^{\mathrm{U}}$ ) at very

525 small strains.

\section{Acknowledgements}

527 The Authors acknowledge EPSRC for their funding of the research described [Grant numbers

$528 \mathrm{EP} / \mathrm{E} 029957 / 1, \mathrm{EP} / \mathrm{D} 506387 / 1]$ as well as their former colleagues Dr Nguyen Anh-Minh,

529 Prof Matthew Coop, Dr Apollonia Gasparre, Dr Clark Fenton, Dr Ramtin Hosseini-Kamal

530 and Dr Stephen Wilkinson who undertook parallel research into the same stiff clays. The

531 contributions made by the Imperial College technicians Alan Bolsher, Steven Ackerley and

532 Graham Keefe are also acknowledged gratefully. 


\section{References}

Addenbrooke, T. I., Potts, D. M., and Puzrin, A. M. 1997. The influence of pre-failure soil stiffness on the numerical analysis of tunnel construction. Géotechnique, 47(3), 693712. doi: 10.1680/geot.1997.47.3.693

Anh-Minh, N. 2007. An investigation of the anisotropic stress-strain-strength characteristics of an Eocene clay. PhD thesis, Department of Civil and Environmental Engineering, Imperial College London, London, UK.

Anh-Minh, N., Nishimura, S., Takahashi, A., and Jardine, R. J. 2011. On the control systems and instrumentation required to investigate the anisotropy of stiff clays and mudrocks through Hollow Cylinder Tests. In Proceedings of the Fifth International Symposium on Deformation Characteristics of Geomaterials, Seoul, Korea, 1-3 September 2011, IOS Press. Vol. 2, pp. 287-294. doi: 10.3233/978-1-60750-822-9-287

Ashmawy, A. K., and Drnevich, V. P. 1994. A general dynamic model for the resonant column/quasi-static torsional shear apparatus. Geotechnical Testing Journal, 17(3): 337-337. doi: 10.1520/GTJ10108J

Brosse, A. M. 2012. Study on the anisotropy of British stiff clays using a Hollow Cylinder Apparatus. PhD thesis, Department of Civil and Environmental Engineering, Imperial College London, London, UK.

Brosse, A. M., Jardine, R. J., and Nishimura, S. 2016. The undrained shear strength anisotropy of four Jurassic to Eocene stiff clays. Submitted to Geotechnique.

Burland, J. B., and Symes, M. 1982. A simple axial displacement gauge for use in the triaxial apparatus. Géotechnique, 32(1): 62-65. doi: 10.1680/geot.1982.32.1.62

Clayton, C. R. I. and Heymann, G. 2001. Stiffness of geomaterials at very small strains. Géotechnique, 51(3): 245-255. doi: 10.1680/geot.2001.51.3.245 
Costa-Filho, L.M. 1980. A laboratory investigation of the small strain behaviour of London clay. PhD Thesis, Department of Civil and Environmental Engineering, Imperial College London, London, UK.

Gasparre, A. 2005. Advanced laboratory characterisation of London clay. Ph.D. thesis, Department of Civil and Environmental Engineering, Imperial College London, London, UK.

Gasparre, A., Nishimura, S., Coop, M. R., and Jardine, R. J. 2007a. The influence of structure on the behaviour of London Clay. Géotechnique, 57(1), 19-31.

doi: 10.1680/geot.2007.57.1.19

Gasparre, A., Nishimura, S., Anh-Minh, N., Coop, M. R., and Jardine, R. J. 2007b. The stiffness of natural London clay. Géotechnique, 57(1), 33-48. doi: 10.1680/geot.2007.57.1.33

Gasparre, A., Hight, D. W., Coop M. R., and Jardine, R. J. 2014. The laboratory measurement and interpretation of the small strain stiffness of stiff clays. Géotechnique, 64(12): 942-953. doi: 10.1680/geot.13.P.227

Gibson, R. E. 1974. The analytical method in soil mechanics. Géotechnique, 24(2): 115-140. doi: 10.1680/geot.1974.24.2.115

Hight, D. W., Gens A., and Symes, M. J. 1983. The development of a new hollow cylinder appparatus for investigating the effects of principal stress rotation in soils. Géotechnique, 33(4): 355-384. doi: 10.1680/geot.1983.33.4.355

Hight, D. W., Gasparre, A., Nishimura, S., Minh, N. A., Jardine, R. J., and Coop, M. R. 2007. Characteristics of the London Clay from the Terminal 5 site at Heathrow Airport. Géotechnique, 57(1), 3-18. doi: 10.1680/geot.2007.57.1.3 
Hosseini-Kamal, R. 2012. Experimental study of the geotechnical properties of UK mudrocks. PhD thesis, Department of Civil and Environmental Engineering, Imperial College London, London, UK.

Hosseini-Kamal, R., Coop, M. R., Jardine, R. J., and Brosse, A. 2014. The post-yield behaviour of four Eocene-to-Jurassic UK stiff clays. Géotechnique, 65(8), 620-634. doi: 10.1680/geot.13.P.043

Jardine, R. J. 1985. Investigations of pile soil behaviour. PhD thesis, Department of Civil and Environmental Engineering, Imperial College London, London, UK.

Jardine, R. J. 1992. Observations on the kinematic nature of soil stiffness at small strains. Soils and Foundations, 32(2): 111-124. doi: 10.3208/sandf1972.32.2_111

Jardine, R. J. 1994. One perspective on the pre-failure deformation characteristics of some geomaterials. In Proceedings of the International Symposium on pre-failure deformation characteristics of geomaterials. Sapporo, Japan, 12-14 September 1994, Volume 2, pp. 885-886.

Jardine, R. J. 2014. Advanced laboratory testing in research and practice: the 2nd Bishop Lecture. Geotechnical research, 1(1): 2-31. doi: 10.1680/geores.14.00003

Jardine, R. J., Symes, M. J., and Burland, J. B. 1984. The measurement of soil stiffness in the triaxial apparatus. Géotechnique, 34(3), 323-340. doi: 10.1680/geot.1984.34.3.323

Jardine, R. J, Gens, A., Hight, D. W., and Coop, M. R. 2004. Developments in understanding soil behaviour. In Advances in Geotechnical Engineering. Proceedings of the Skempton Memorial Conference, London, UK, 29-31 March 2004. Thomas Telford, London, pp. 103-207

Jardine, R. J., Standing, J. R., and Kovacevic, N. 2005. Lessons learned from full scale observations and the practical application of advanced testing and modeling. In Proceedings of the 3rd International Symposium on Deformation Characteristics of 
Geomaterials, Lyon, France. Balkema, Lisse, Volume 2, pp. 201-245.

Kuwano, R., and Jardine, R. J. 1998. Stiffness measurements in a stress path cell. In Prefailure behaviour of geomaterials. Thomas Telford, London, pp 391-395.

Kuwano, R., and Jardine, R. J. 2007. A triaxial investigation of kinematic yielding in sand. Géotechnique, 57(7): 563-580. doi: 10.1680/geot.2007.57.7.563

Love, A. E. H. 1927. A treatise on the mathematical theory of elasticity. Cambridge University Press, Cambridge, UK.

Mayne, P. W., and Kulhawy, F. H. 1982. K ${ }_{0}$-OCR Relationships in Soil. Journal of the Soil Mechanics and Foundations Division, 108(6): 851-872.

Nishimura, S. 2006. Laboratory study of the anisotropy of natural London Clay. PhD Thesis, Department of Civil and Environmental Engineering, Imperial College London, London, UK.

Nishimura, S. 2014a. Cross-anisotropic deformation characteristics of natural sedimentary clays, Géotechnique, 64(12) 981-996. doi: 10.1680/geot.14.P.088

Nishimura, S. 2014b. Assessment of anisotropic elastic parameters of saturated clay measured in triaxial apparatus: Appraisal of techniques and derivation procedures. Soils and Foundations, 54(3) 364-376. doi:10.1016/j.sandf.2014.04.006

Nishimura, S., Minh, N. A., and Jardine, R. J. 2007. Shear strength anisotropy of natural London Clay. Géotechnique 57(1), 49-62. doi: 10.1680/geot.2007.57.1.49

Pennington, D. S., Nash, D. F. T., and Lings M. L. 1997. Anisotropy of $\mathrm{G}_{0}$ shear stiffness in Gault clay. Géotechnique, 47(3), 391-398. doi: 10.1680/geot.1997.47.3.391

Potts, D. M., and Zdravkovic, L. 1999. Finite element analysis in geotechnical engineering: theory. Thomas Telford, London, UK. doi: 10.1680/feaiget.27534

Potts, D. M., and Zdravkovic, L. 2001. Finite element analysis in geotechnical engineering: application. Thomas Telford, London, UK. doi: 10.1680/feaigea.27831 
Simpson, B., Atkinson, J. H., and Jovicic, V. 1996. The influence of anisotropy on calculation of ground settlements above tunnels. In Geotechnical aspects of underground construction in soft ground (eds R. J. Mair and R. N. Taylor), pp. 591-595. Rotterdam: Balkema.

Tatsuoka, F., Jardine, R. J., Lo Presti, D., Di Benedetto, H., and Kodaka, T. 1997. Characterising the pre-failure deformation properties of geomaterials. In Proceeding of the $14^{\text {th }}$ International Conference on Soil Mechanics and Foundation Engineering, Hamburg. Balkema, Rotterdam, Volume 4, pp 2129-2164

Vucetic, M. 1994. Cyclic threshold shear strains in soils. Journal of Geotechnical Engineering, 120(12): 2208-2228. Doi: 10.1061/(ASCE)07339410(1994)120:12(2208)

Wilkinson, S. 2011. The micro-structure of UK mudrocks. Ph.D thesis, Department of Civil and Environmental Engineering, Imperial College London, London, UK. 


\section{List of symbols}

$\alpha \quad$ Angle between the vertical and the direction of the major principal stress $\sigma_{1}$

$\alpha_{d \sigma} \quad$ Angle between the vertical and the direction of the increment in $\Delta \sigma_{1}$

$\alpha_{f} \quad$ Angle between the vertical and the direction of $\sigma_{1}$ axis at peak $q$

$\varepsilon_{1}, \varepsilon_{2}, \varepsilon_{3} \quad$ Major, intermediate and minor principal strains respectively

$\varepsilon_{z}, \varepsilon_{r}, \varepsilon_{\theta} \quad$ Axial, radial and circumferential strains respectively

$\gamma \quad$ Bulk unit weight

$\gamma_{z \theta} \quad$ Shear strain in the axial-circumferential plane

$\phi^{\prime} \quad$ Effective angle of shearing resistance

$\sigma_{1}, \sigma_{2}, \sigma_{3} \quad$ Major, intermediate and minor principal stresses respectively

$\sigma_{z}, \sigma_{r}, \sigma_{\theta} \quad$ Axial, radial and circumferential stresses respectively

$\mu_{\mathrm{vh}} \quad$ Poisson ratio for the influence of increments of vertical stress on horizontal strain

$\mu_{\mathrm{hv}} \quad$ Poisson ratio for the influence of increments of horizontal stress on vertical strain

$\mu_{\mathrm{hh}} \quad$ Poisson ratio for the influence of increments of horizontal stress on horizontal strain

$\tau_{z \theta}, \tau_{z r}, \tau_{r \theta} \quad$ Shear stresses in the axial-circumferential, axial-radial and radialcircumferential planes respectively

B Coefficient of saturation

$b \quad$ Intermediate principal stress factor

e Void ratio

$\mathrm{E}_{\mathrm{v}}, \mathrm{E}_{\mathrm{h}} \quad$ Vertical and horizontal Young's moduli respectively

Ghh Shear modulus in horizontal plane 


\begin{tabular}{|c|c|}
\hline Ghv, Gvh & Shear moduli in vertical plane \\
\hline $\mathrm{G}_{\mathrm{z} \theta}\left(=\mathrm{G}_{\mathrm{vh}}\right)$ & Shear moduli in the axial-circumferential (vertical) plane \\
\hline $\mathrm{HCA}$ & Hollow Cylinder Apparatus \\
\hline ICRCHCA & Imperial College Resonant Column Hollow Cylinder Apparatus \\
\hline ICHCA II & Imperial College Hollow Cylinder Apparatus Mark II \\
\hline $\mathrm{K}_{0}$ & Coefficient of earth pressure at rest \\
\hline OCR & Overconsolidation Ratio \\
\hline$p^{\prime}$ & Mean effective stress \\
\hline$p_{0}^{\prime}$ & In-situ mean effective stress \\
\hline PL, LL & Plastic Limit, Liquid Limit \\
\hline$q$ & Deviatoric stress $\left(=\sigma_{1}^{\prime}-\sigma_{3}^{\prime}\right)$ \\
\hline$s^{\prime}$ & $\left(\sigma_{1}+\sigma_{3}\right) / 2$ \\
\hline $\mathrm{S}_{\mathrm{u}}$ & Undrained shear strength \\
\hline SBPM & Self-Boring Pressuremeter \\
\hline$t$ & $\left(\sigma_{1}^{\prime}-\sigma_{3}^{\prime}\right) / 2$ \\
\hline TC & Triaxial Compression test \\
\hline $\mathrm{TE}$ & Triaxial Extension test \\
\hline$v$ & Specific Volume \\
\hline
\end{tabular}




\section{Figures Captions}

Figure 1. Schematic diagram of the Imperial College Resonant Column Hollow Cylinder Apparatus - ICRCHCA (modified from Nishimura 2006; Brosse 2012)

Figure 2. Schematic diagram of the Imperial College Hollow Cylinder Apparatus Mark II ICHCA II (Anh-Minh 2007)

Figure 3. Schematic of the undrained stress paths followed during shearing from in-situ stresses in the HCA 'constant $\alpha_{\mathrm{d} \sigma}-b=0.5$ ' test series.

Figure 4. Strain and stress variations with time during test OA2305 $\left(\alpha_{f}=23^{\circ}\right.$ at $\left.b=0.5\right)-(\mathrm{a})$ Strains; (b) Stresses

Figure 5. Comparison of the undrained Young's moduli degradation curves before and after post-processing of the data for OA2305 $\left(\alpha_{f}=23^{\circ}\right.$ at $\left.b=0.5\right)$.

Figure 6. Comparison of secant $\mathrm{E}_{\mathrm{v}}^{\mathrm{U}}$ degradation curves at different $\alpha_{f}$ for Oxford clay test series.

Figure 7. Comparison of secant $\mathrm{E}_{\mathrm{h}}^{\mathrm{U}}$ degradation curves at different $\alpha_{f}$ for Oxford clay test series.

Figure 8. Comparison of secant $\mathrm{E}_{\mathrm{v}}^{\mathrm{U}}$ degradation curves at different $\alpha_{f}$ for Kimmeridge clay test series.

Figure 9. Comparison of secant $\mathrm{E}_{\mathrm{h}}^{\mathrm{U}}$ degradation curves at different $\alpha_{f}$ for Kimmeridge clay test series.

Figure 10. Comparison of secant $\mathrm{E}_{\mathrm{v}}^{\mathrm{U}}$ degradation curves at different $\alpha_{f}$ for Gault clay test series.

Figure 11. Comparison of secant $\mathrm{E}_{\mathrm{h}}^{\mathrm{U}}$ degradation curves at different $\alpha_{f}$ for Gault clay test series. 
Figure 12. Comparison of secant $\mathrm{E}_{\mathrm{v}}^{\mathrm{U}}$ degradation curves at different $\alpha_{f}$ for London clay test series.

Figure 13. Comparison of secant $\mathrm{E}_{\mathrm{h}}^{\mathrm{U}}$ degradation curves at different $\alpha_{f}$ for London clay test series.

Figure 14. Comparison of secant $\mathrm{G}_{z} \theta$ degradation curves at different $\alpha_{f}$ for Oxford clay test series.

Figure 15. Comparison of secant $\mathrm{G}_{z \theta}$ degradation curves at different $\alpha_{f}$ for Kimmeridge clay test series.

Figure 16. Comparison of secant $\mathrm{G}_{z} \theta$ degradation curves at different $\alpha_{f}$ for Gault clay test series.

Figure 17. Comparison of secant $\mathrm{G}_{z \theta}$ degradation curves at different $\alpha_{f}$ for London clay test series.

Figure 18: Example of strain contours and strength envelopes in $\tau_{z \theta}-\left(\sigma_{z}-\sigma_{\theta}\right) / 2$ space for the Oxford clay case. The envelopes and contours are illustrated by fitted ellipses.

Figure 19: Comparison of the variation of the Young's moduli ratio $\mathrm{E}_{\mathrm{h}} \mathrm{U} / \mathrm{E}_{\mathrm{v}} \mathrm{U}$ with axial strain for the different soils (a) at $\alpha_{f}=0^{\circ}$ (b) at $\alpha_{f}=45^{\circ}$ (c) at $\alpha_{f}=90^{\circ}$. 


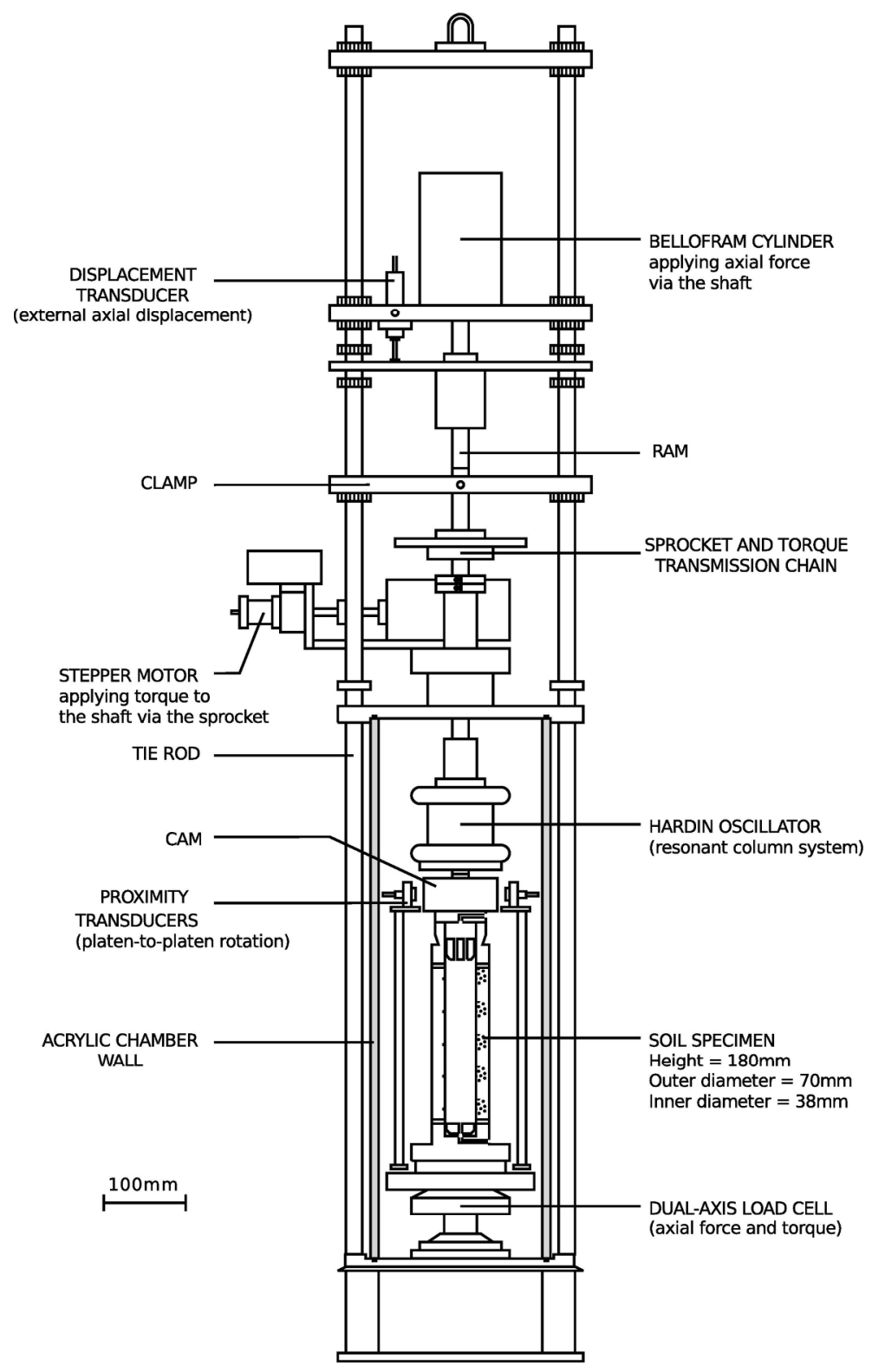

Figure 1. Schematic diagram of the Imperial College Resonant Column Hollow Cylinder Apparatus - ICRCHCA (modified from Nishimura, 2006; Brosse, 2012)

Figure 1

$165 \times 263 \mathrm{~mm}(300 \times 300 \mathrm{DPI})$ 

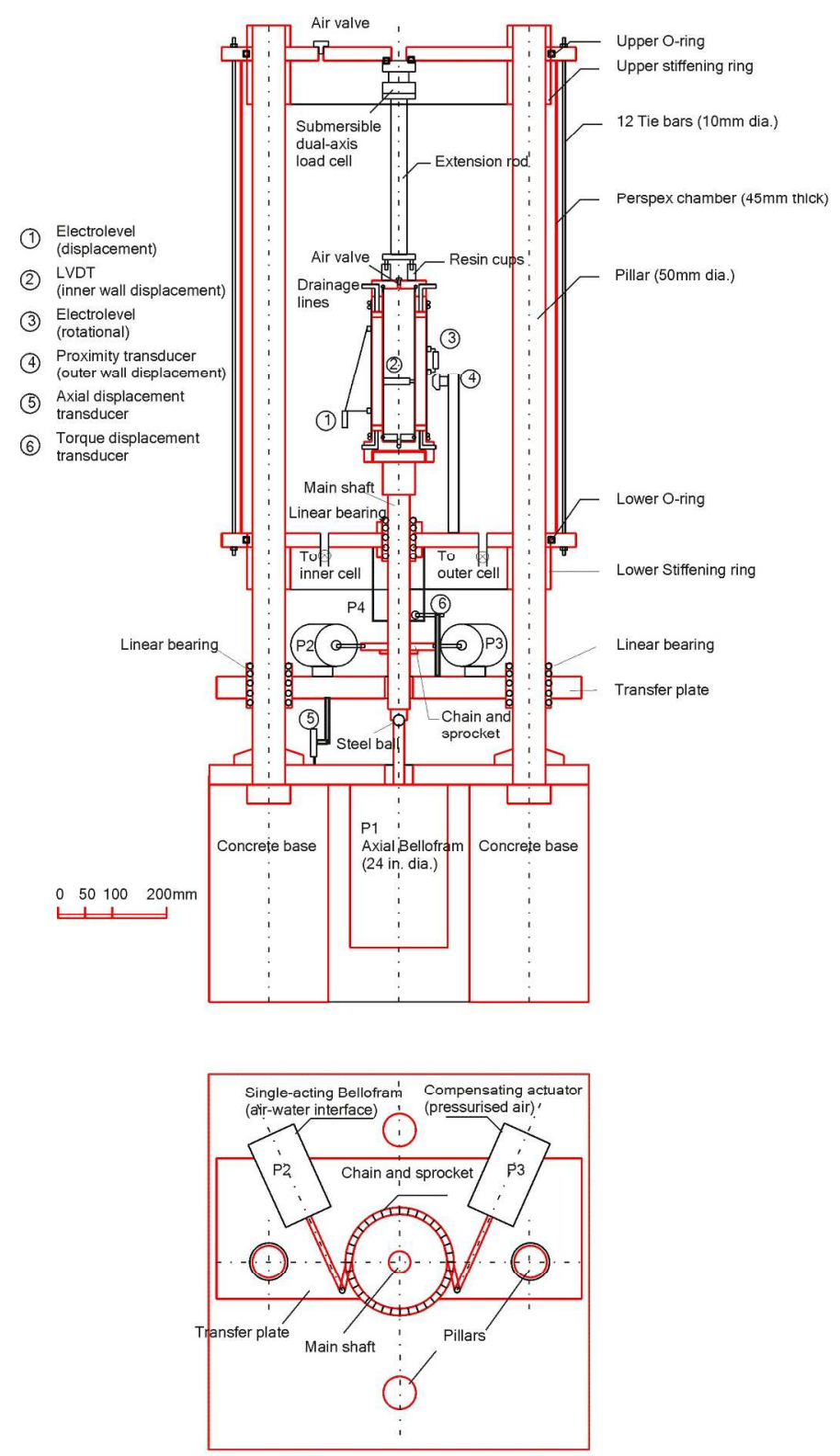

Figure 2. Schematic diagram of the Imperial College Hollow Cylinder Apparatus Mark II - ICHCA II (AnhMinh, 2007)

Figure 2

$225 \times 400 \mathrm{~mm}(300 \times 300$ DPI $)$ 


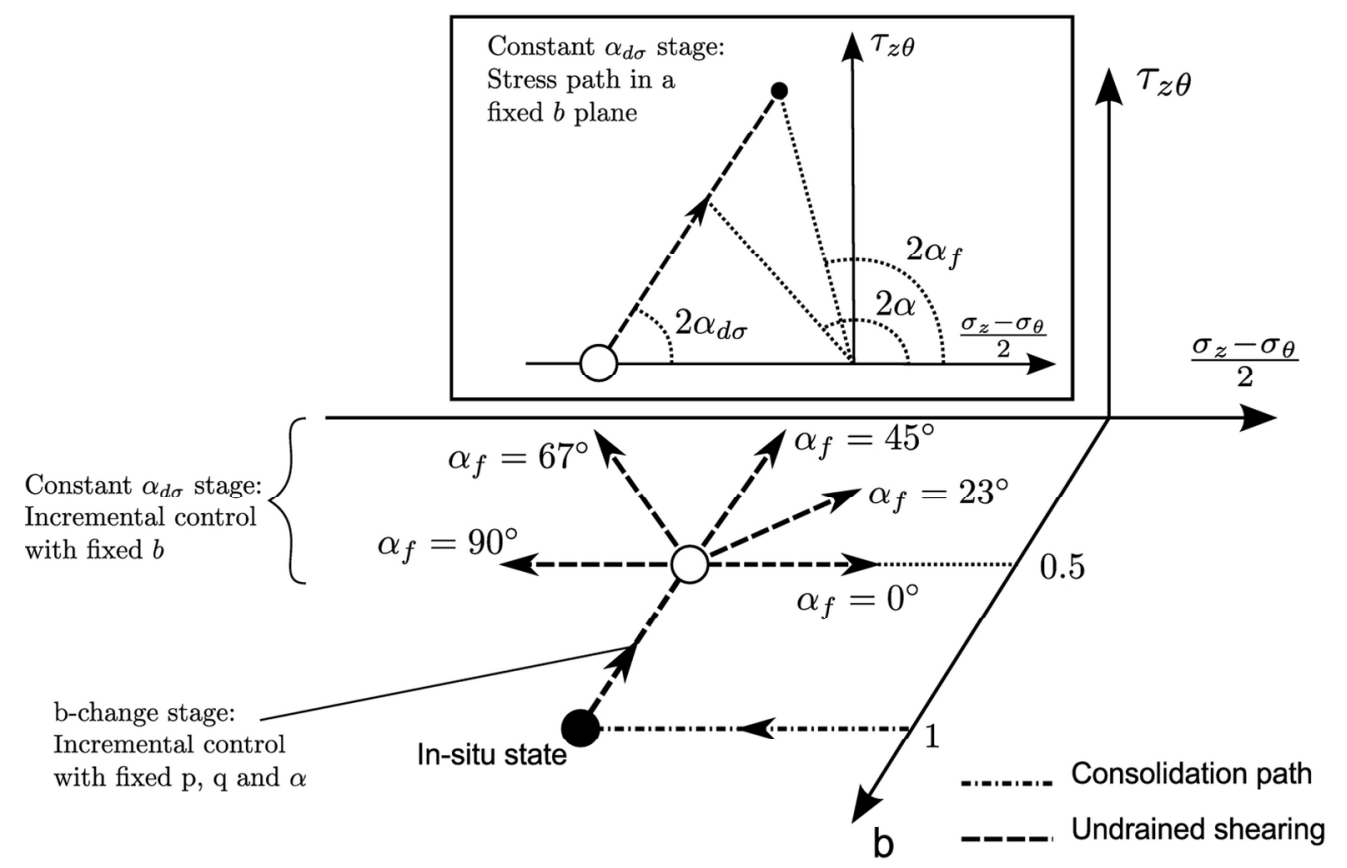

Schematic of the undrained stress paths followed during shearing from in-situ stresses in the HCA 'constant $a_{d \sigma}-b=0.5^{\prime}$ test series.

Figure 3

$130 \times 85 \mathrm{~mm}(300 \times 300 \mathrm{DPI})$ 

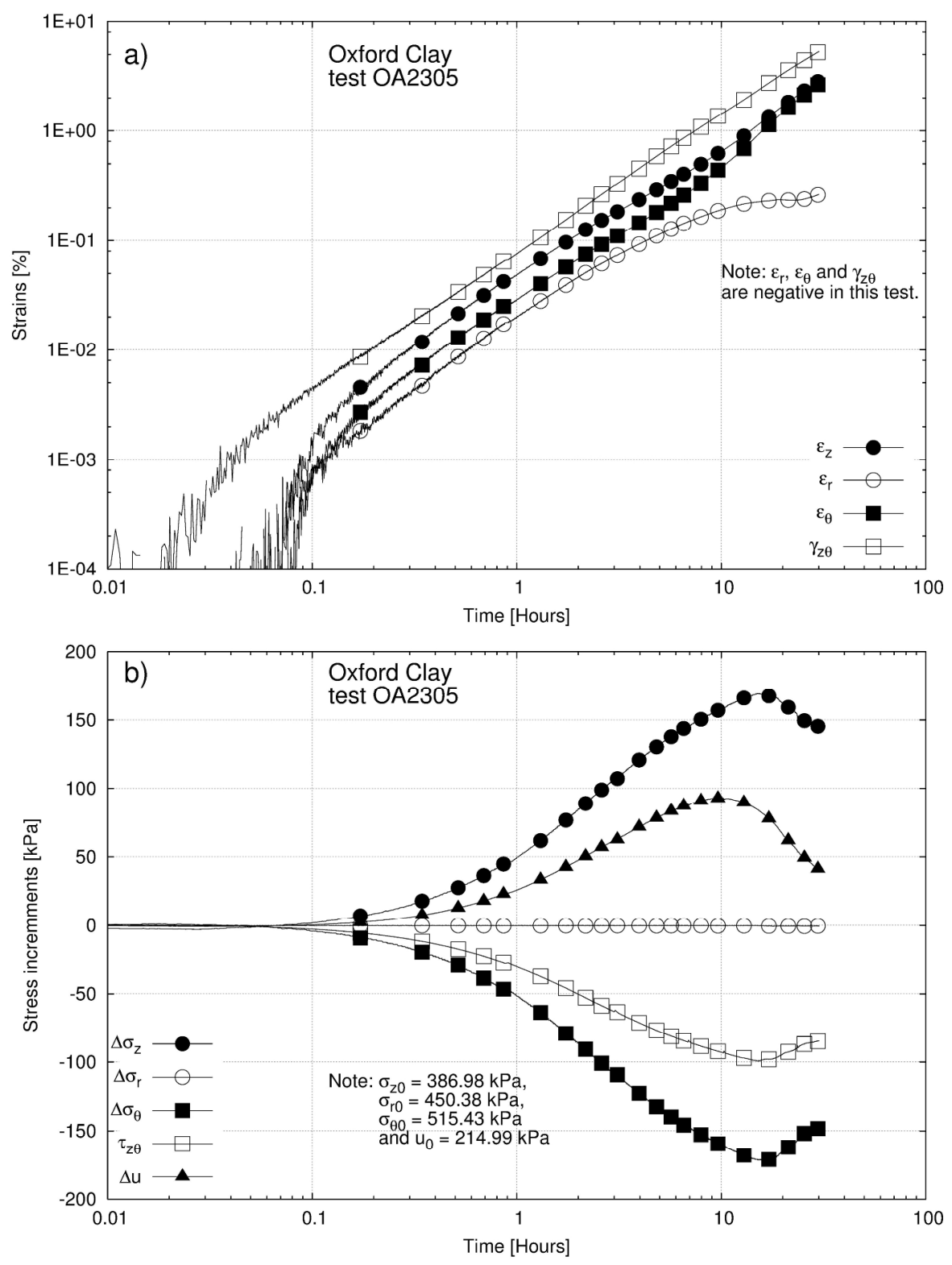

Figure 4. Strain and stress variations with time during test OA2305 $\left(a_{f}=23^{\circ}\right.$ at $\left.b=0.5\right)-(a)$ Strains; (b) Stresses

Figure 4

$236 \times 309 \mathrm{~mm}(300 \times 300$ DPI $)$ 


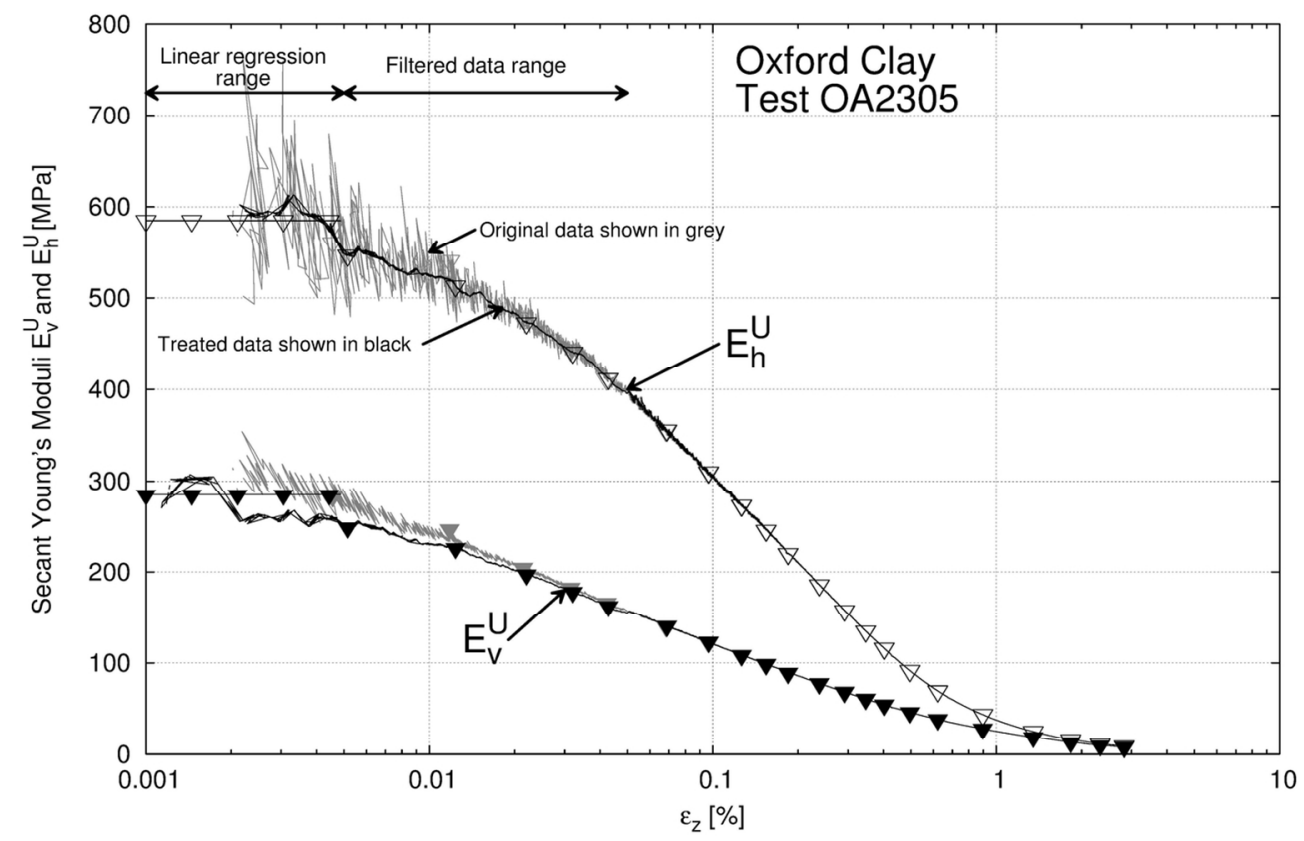

Figure 5. Comparison of the undrained Young's moduli degradation curves before and after post-processing of the data for OA2305 $\left(a_{f}=23^{\circ}\right.$ at $\left.b=0.5\right)$.

Figure 5

$120 \times 80 \mathrm{~mm}(300 \times 300 \mathrm{DPI})$ 


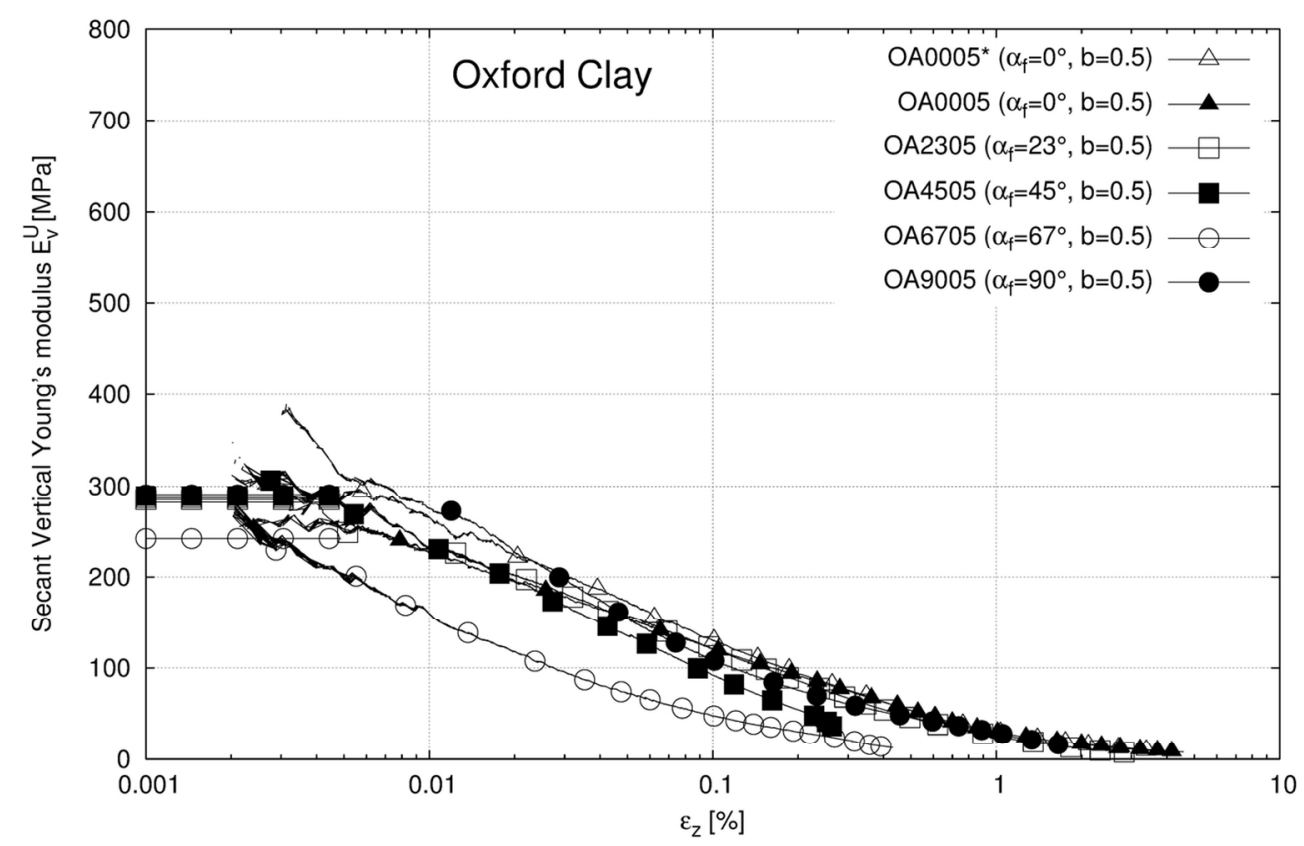

Figure 6. Comparison of secant $E_{v}{ }^{u}$ degradation curves at different $a_{f}$ for Oxford clay test series. Figure 6

$120 \times 80 \mathrm{~mm}(300 \times 300 \mathrm{DPI})$ 


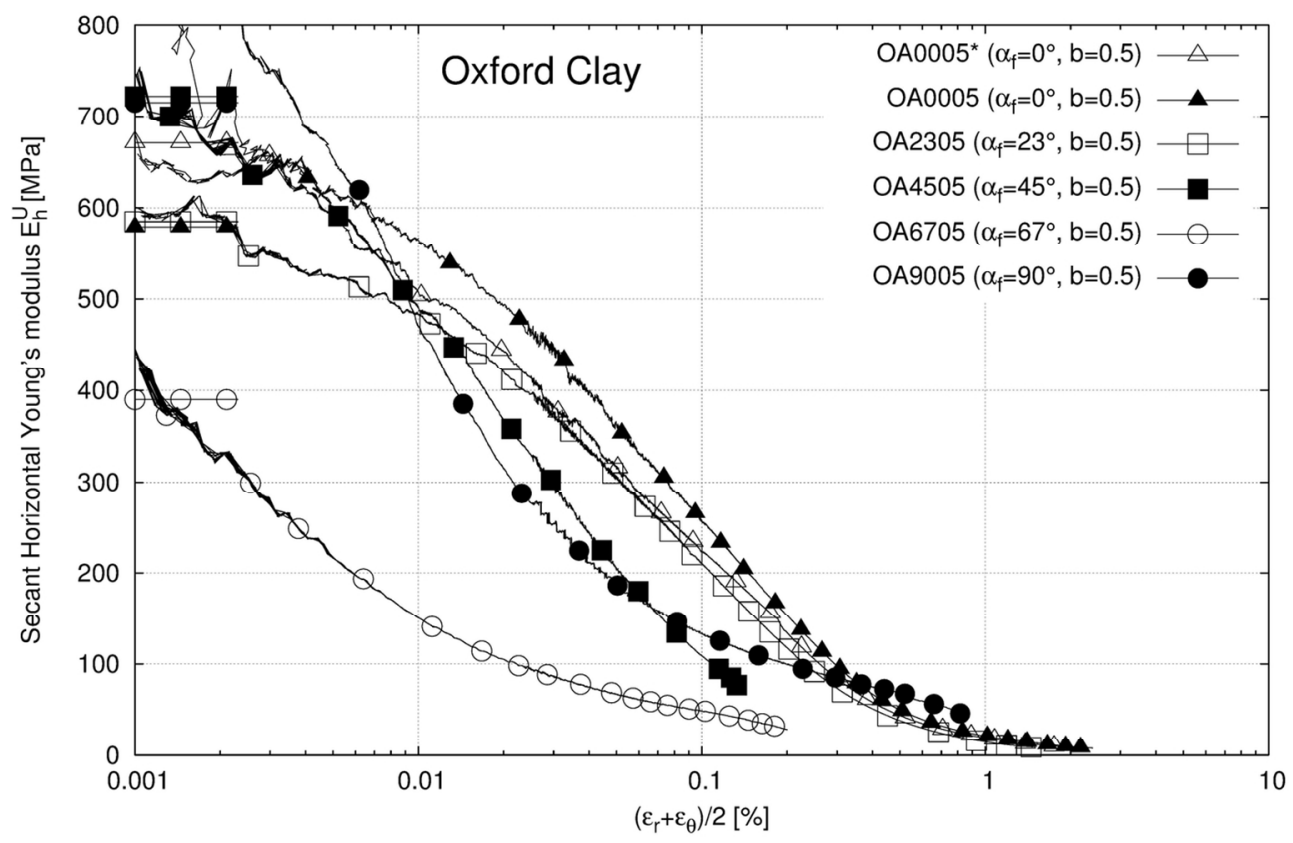

Figure 7. Comparison of secant $\mathrm{E}_{\mathrm{h}}{ }^{\mathrm{U}}$ degradation curves at different $\mathrm{a}_{\mathrm{f}}$ for Oxford clay test series. Figure 7

$120 \times 80 \mathrm{~mm}(300 \times 300$ DPI $)$ 


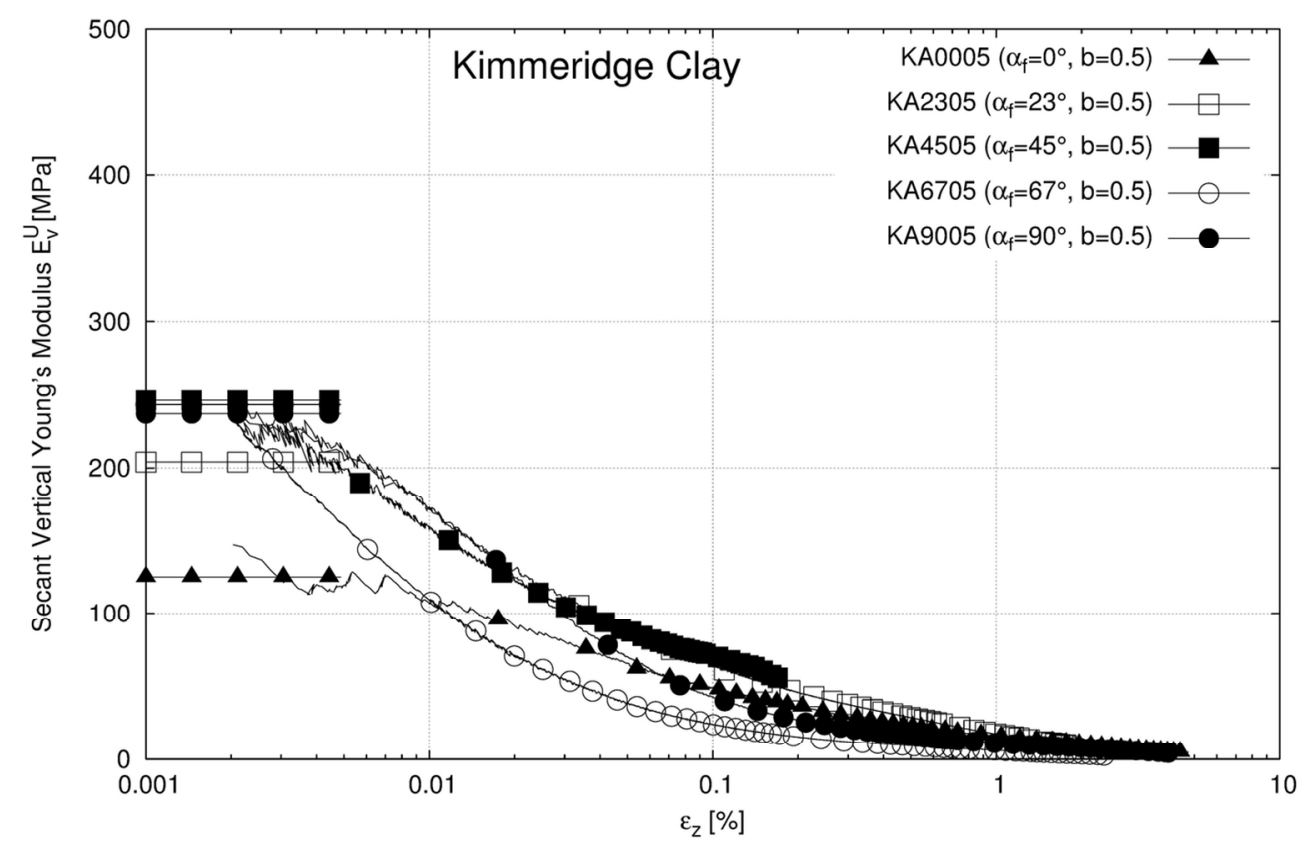

Figure 8. Comparison of secant $E_{v}{ }^{u}$ degradation curves at different $a_{f}$ for Kimmeridge clay test series. Figure 8

$120 \times 80 \mathrm{~mm}(300 \times 300 \mathrm{DPI})$ 


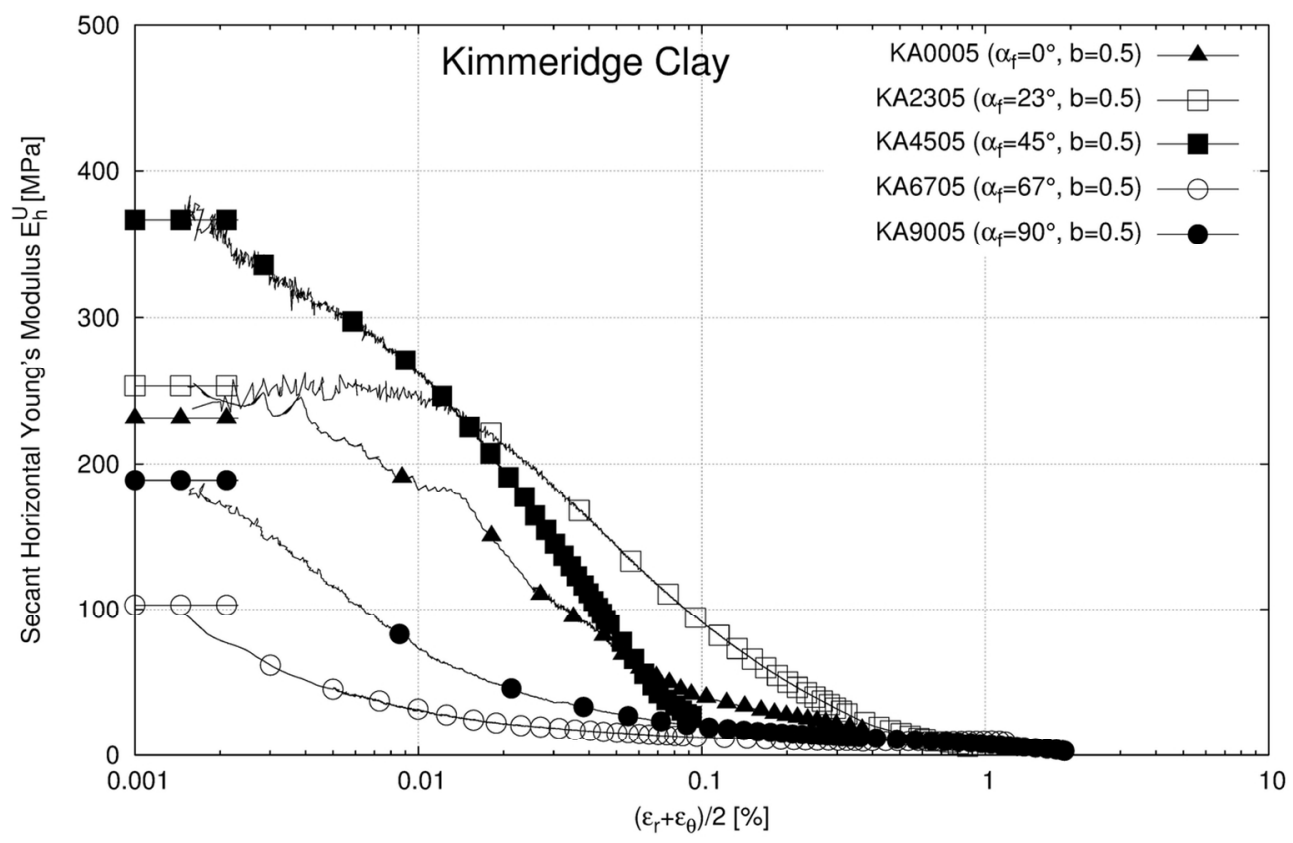

Figure 9. Comparison of secant $E_{h}{ }^{u}$ degradation curves at different $a_{f}$ for Kimmeridge clay test series. Figure 9

$120 \times 80 \mathrm{~mm}(300 \times 300 \mathrm{DPI})$ 


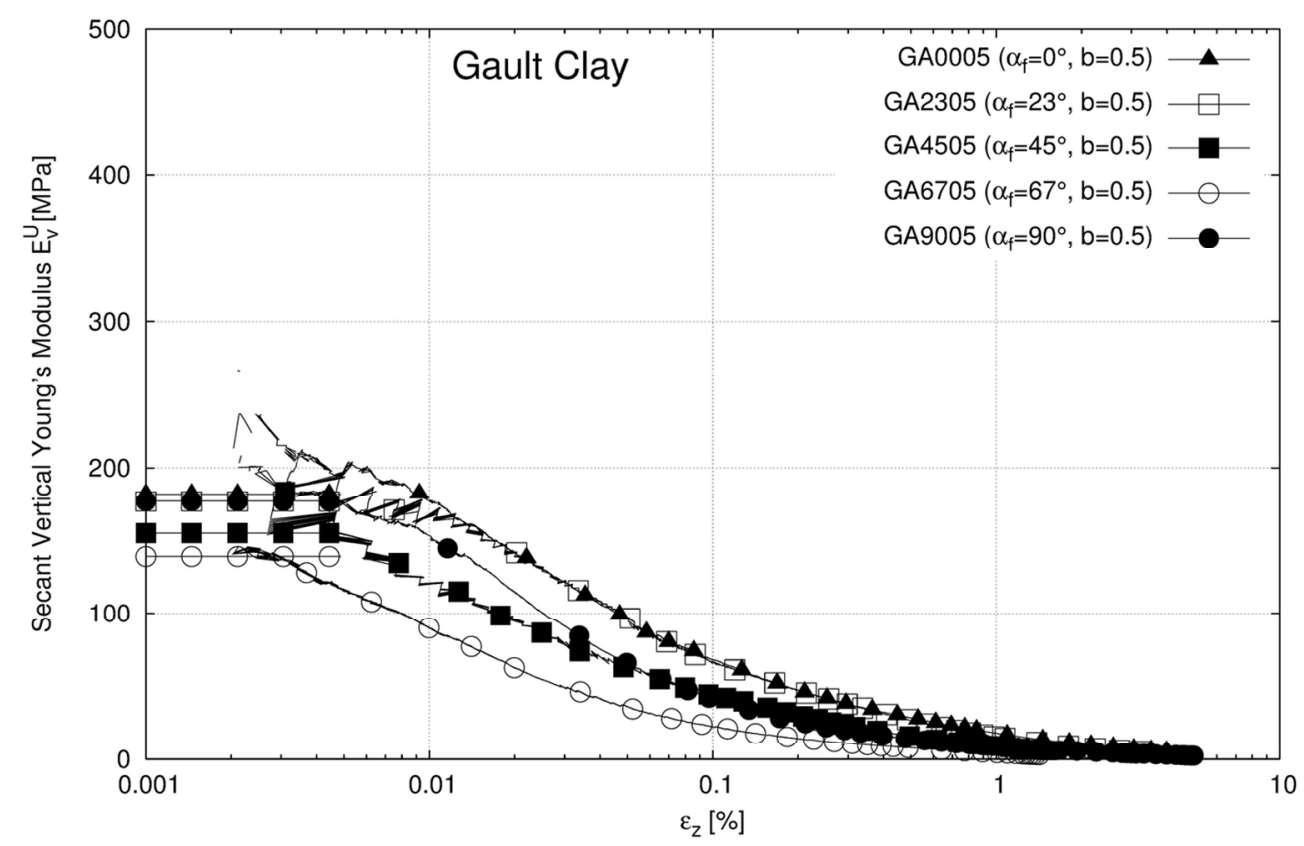

Figure 10. Comparison of secant $E_{v}{ }^{U}$ degradation curves at different $a_{f}$ for Gault clay test series. Figure 10

$120 \times 80 \mathrm{~mm}(300 \times 300 \mathrm{DPI})$ 


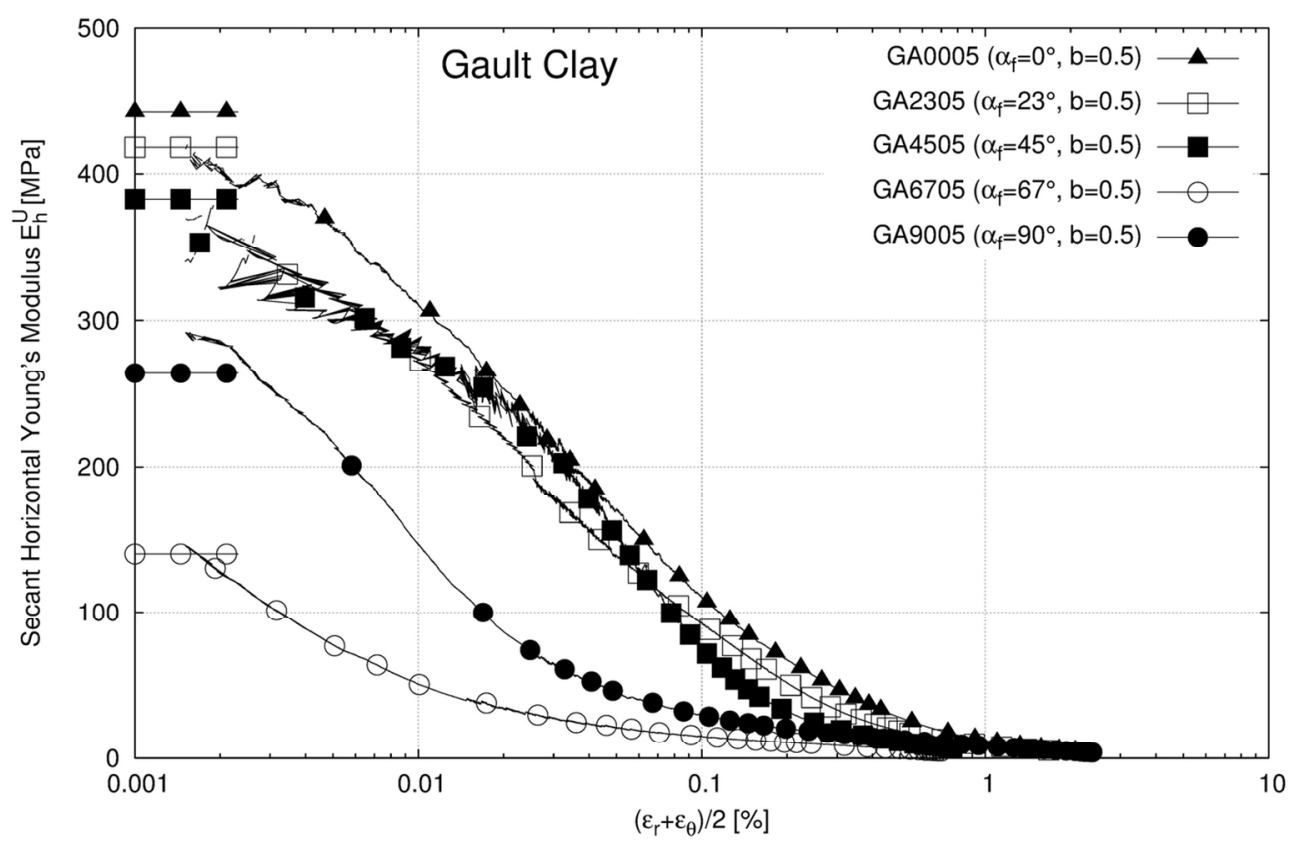

Figure 11. Comparison of secant $\mathrm{E}_{\mathrm{h}}{ }^{\mathrm{U}}$ degradation curves at different $\mathrm{a}_{\mathrm{f}}$ for Gault clay test series. Figure 11

$120 \times 80 \mathrm{~mm}(300 \times 300 \mathrm{DPI})$ 


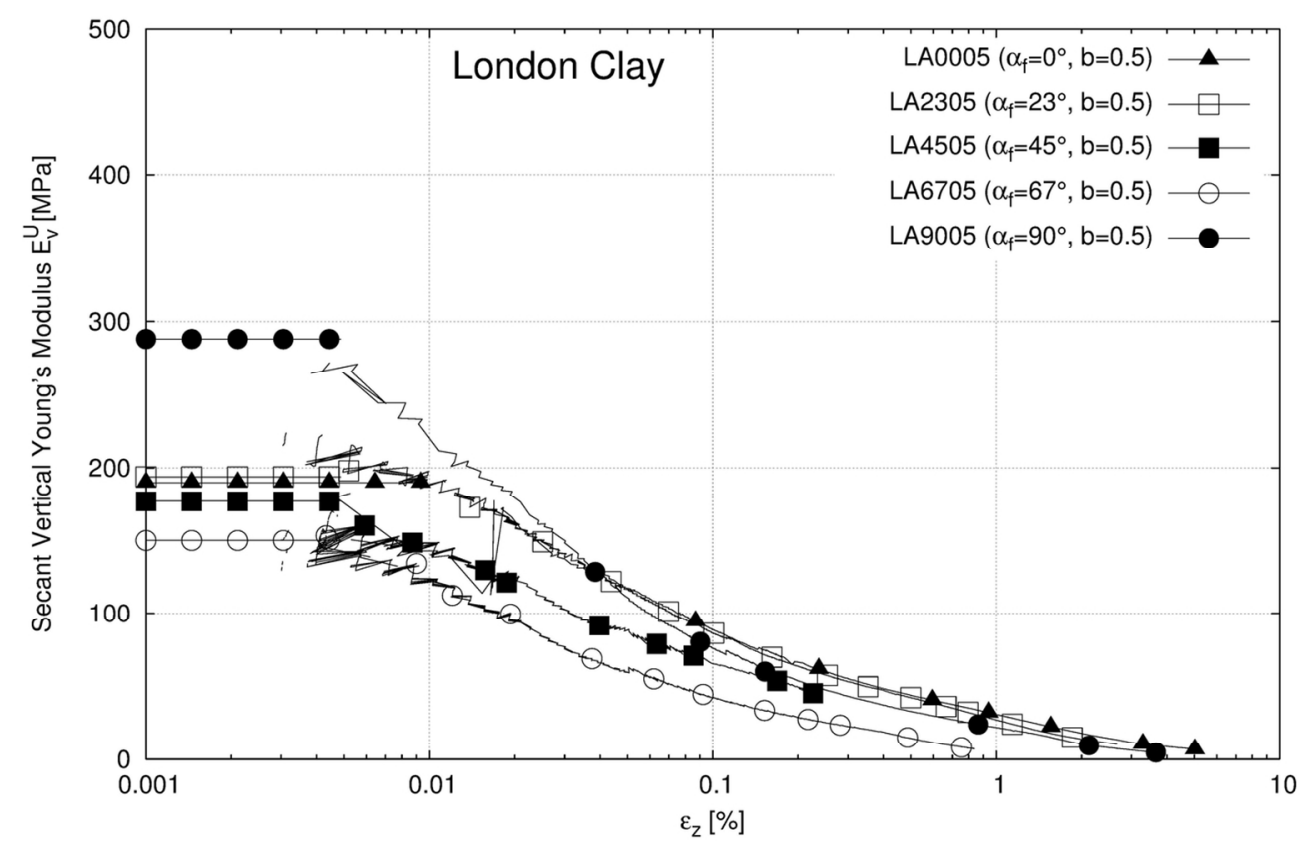

Figure 12. Comparison of secant $\mathrm{E}_{\mathrm{v}}{ }^{\mathrm{U}}$ degradation curves at different $\mathrm{a}_{\mathrm{f}}$ for London clay test series. Figure 12

$120 \times 80 \mathrm{~mm}(300 \times 300$ DPI $)$ 


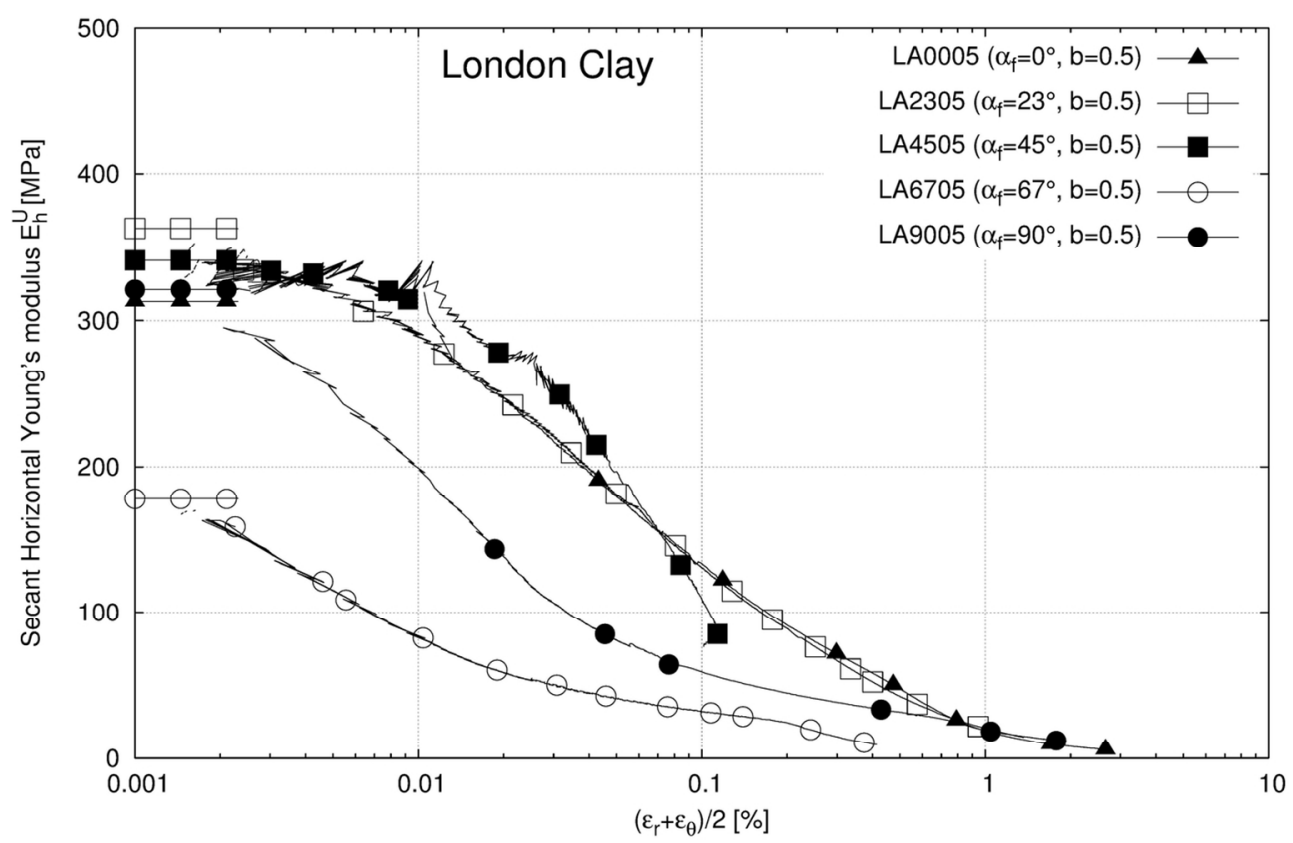

Figure 13. Comparison of secant $E_{h}{ }^{u}$ degradation curves at different $a_{f}$ for London clay test series. Figure 13

$120 \times 80 \mathrm{~mm}(300 \times 300 \mathrm{DPI})$ 


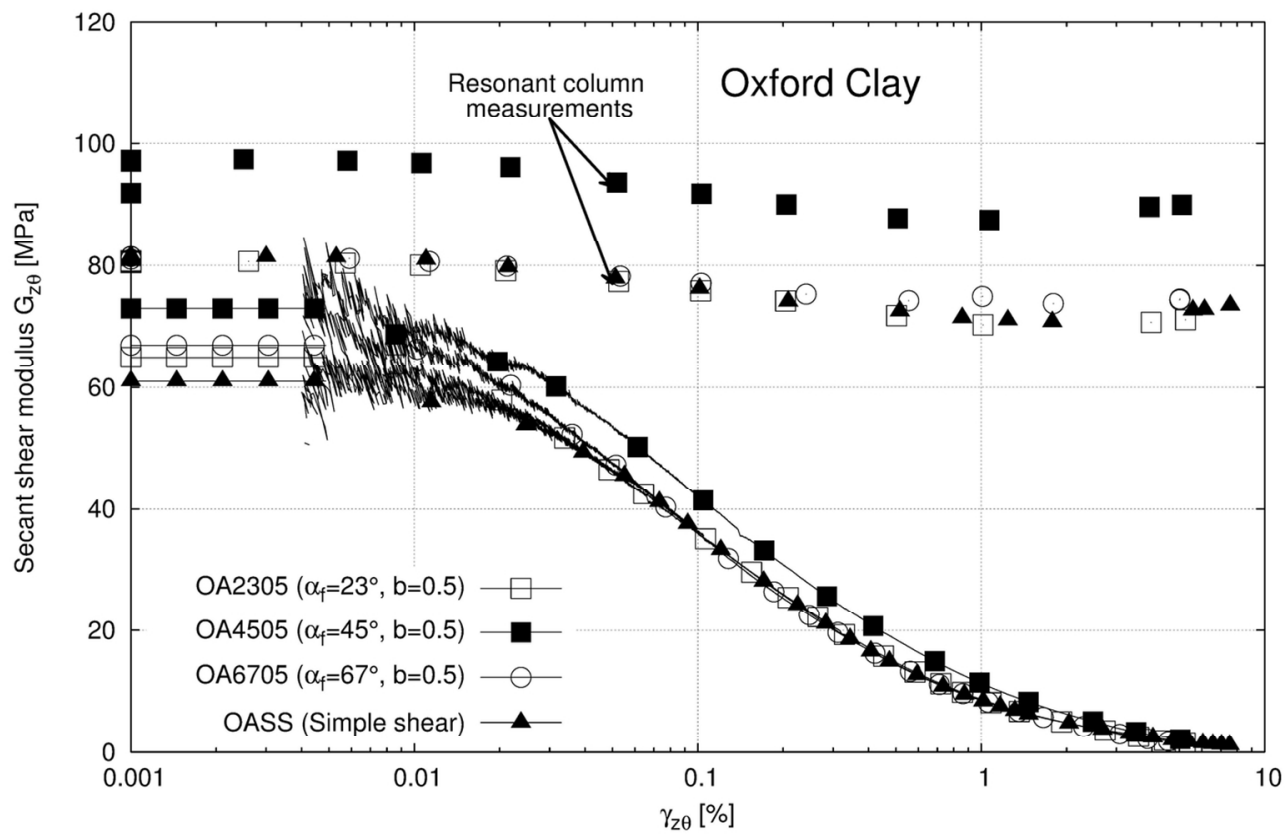

Figure 14. Comparison of secant $\mathrm{G}_{z \theta}$ degradation curves at different $\mathrm{a}_{\mathrm{f}}$ for Oxford clay test series. Figure 14

$120 \times 80 \mathrm{~mm}(300 \times 300 \mathrm{DPI})$ 


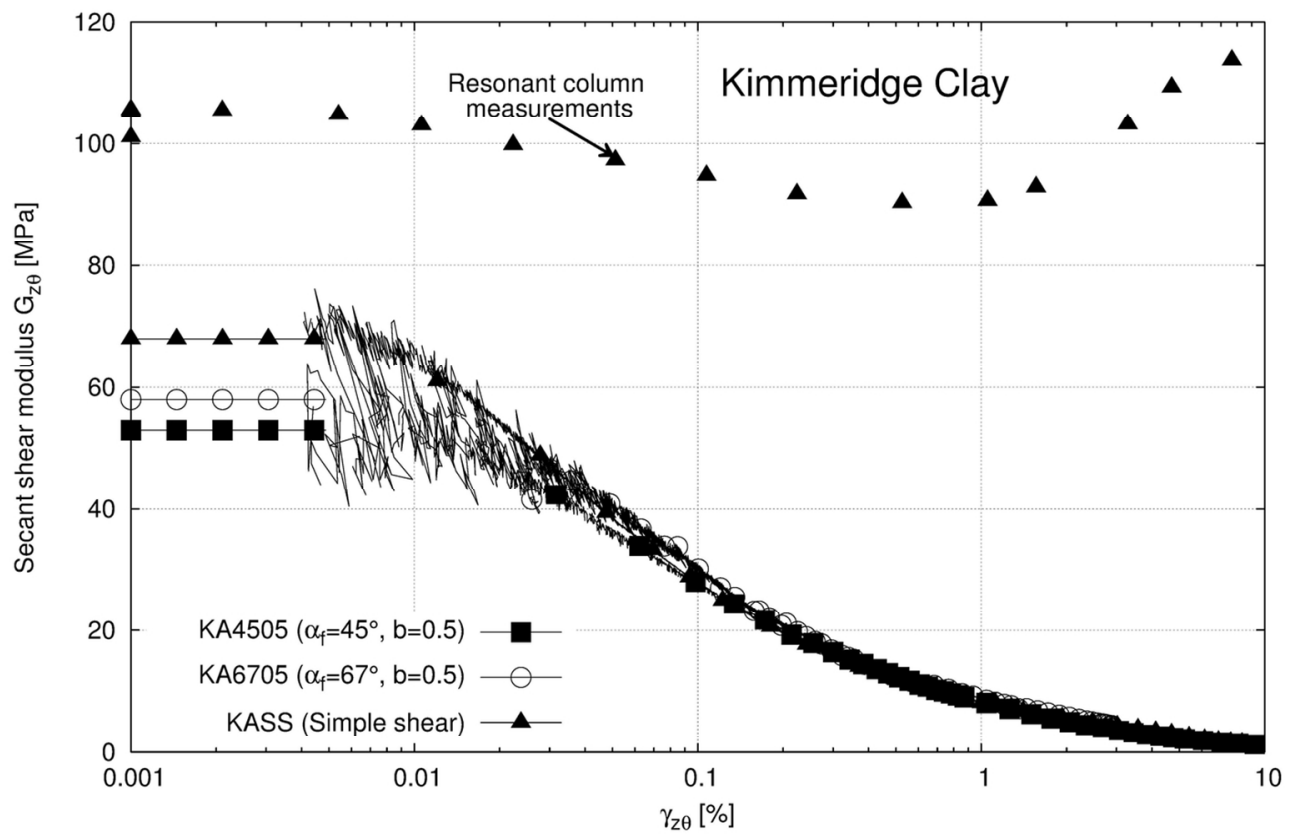

Figure 15. Comparison of secant $\mathrm{G}_{\mathrm{z} \theta}$ degradation curves at different $\mathrm{a}_{\mathrm{f}}$ for Kimmeridge clay test series. Figure 15

$120 \times 80 \mathrm{~mm}(300 \times 300 \mathrm{DPI})$ 


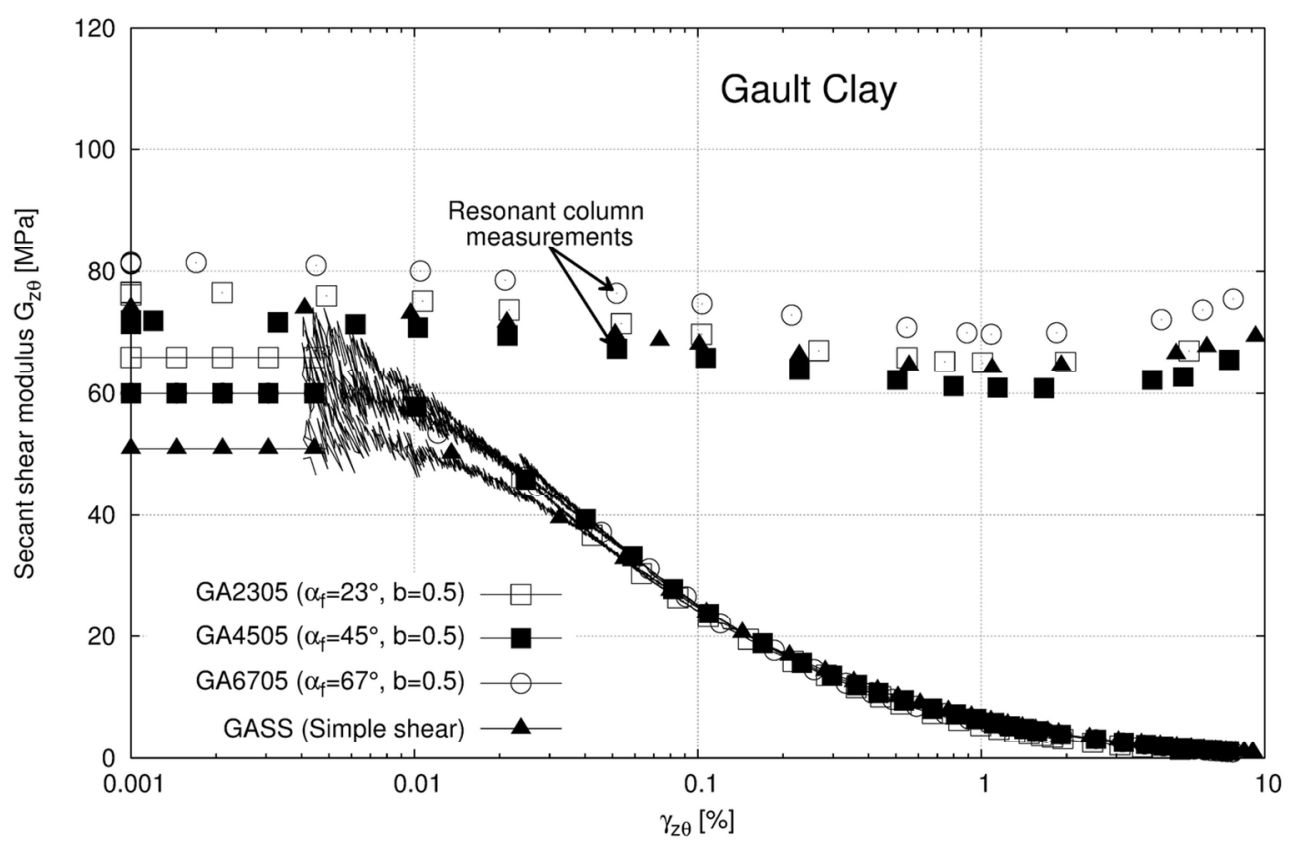

Figure 16. Comparison of secant $\mathrm{G}_{z \theta}$ degradation curves at different $\mathrm{a}_{\mathrm{f}}$ for Gault clay test series. Figure 16

$120 \times 80 \mathrm{~mm}(300 \times 300 \mathrm{DPI})$ 


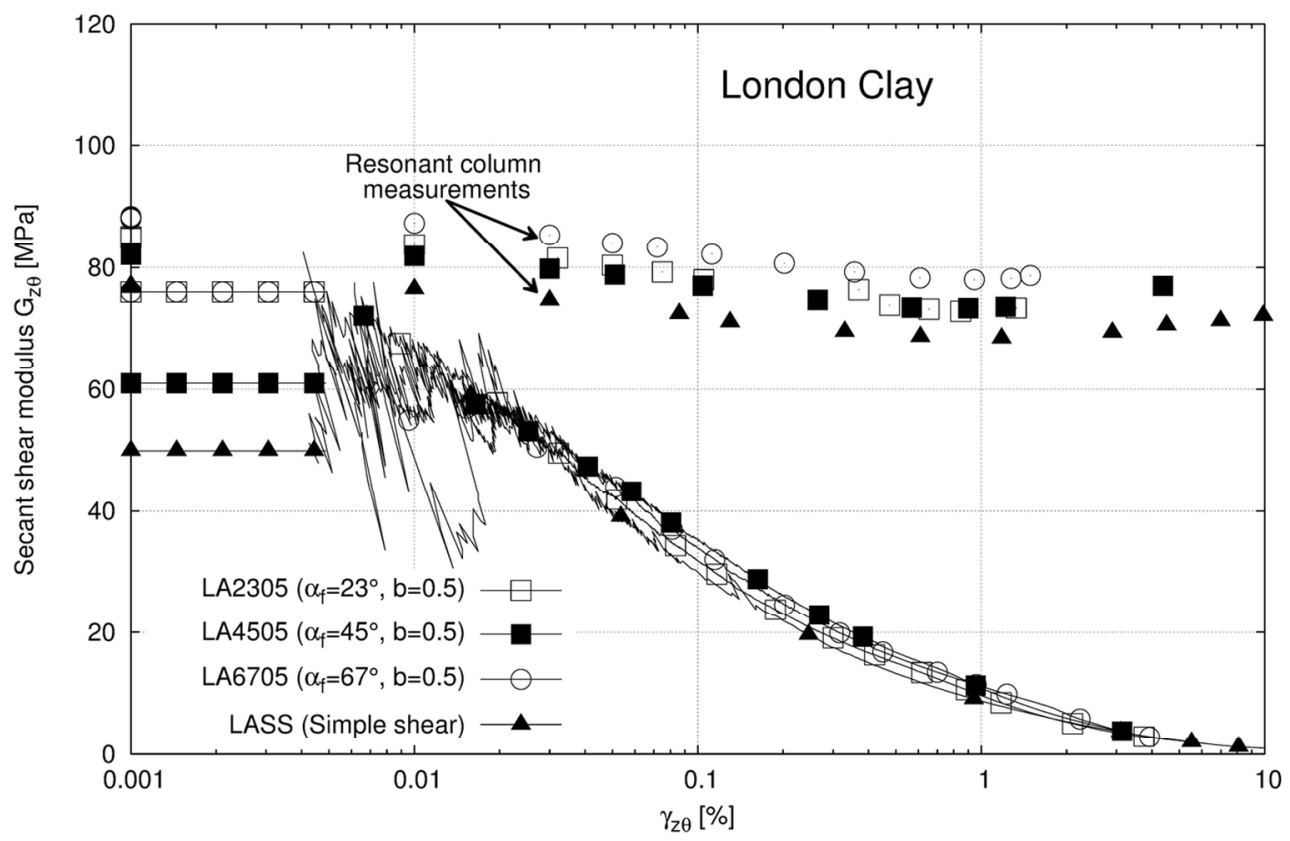

Figure 17. Comparison of secant $G_{z \theta}$ degradation curves at different $a_{f}$ for London clay test series. Figure 17

$120 \times 80 \mathrm{~mm}(300 \times 300$ DPI) 


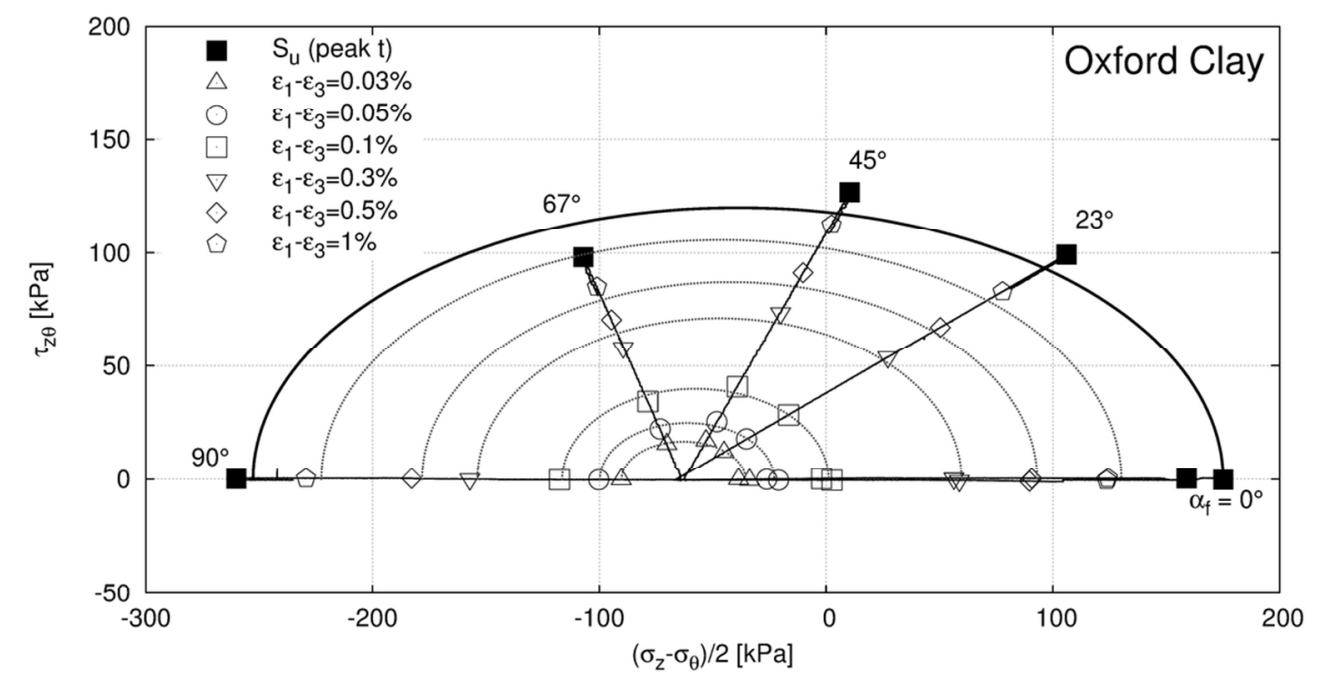

Figure 18: Example of strain contours and strength envelopes in $T_{z \theta}-\left(\sigma_{z}-\sigma_{\theta}\right) / 2$ space for the Oxford clay case. The envelopes and contours are illustrated by fitted ellipses.

Figure 18

$99 \times 54 \mathrm{~mm}(300 \times 300$ DPI $)$ 

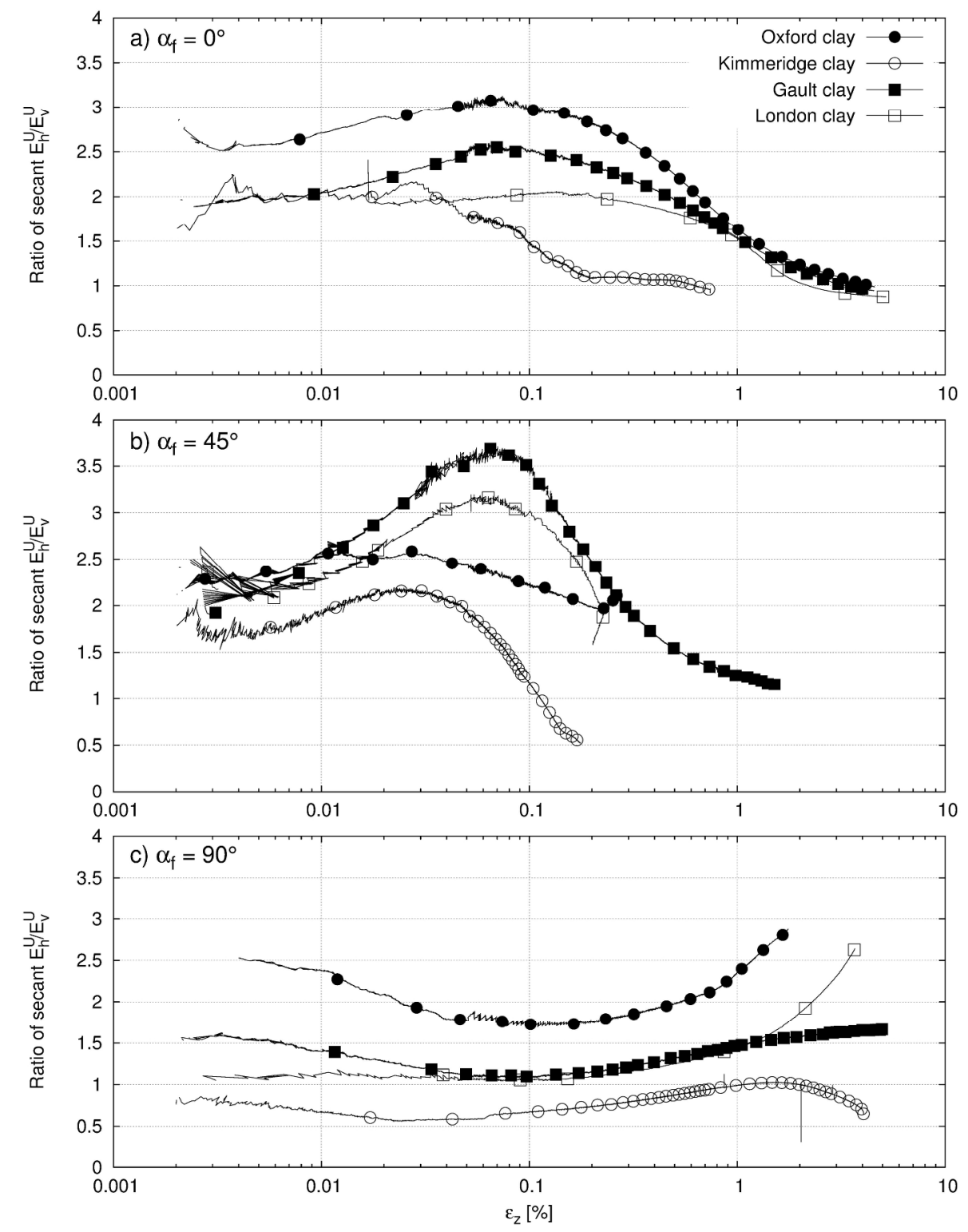

Figure 19: Comparison of the variation of the Young's moduli ratio $E_{h}{ }^{U} / E_{v}{ }^{U}$ with axial strain for the different soils (a) at $a_{f}=0^{\circ}\left(\right.$ b) at $a_{f}=45^{\circ}$ (c) at $a_{f}=90^{\circ}$.

Figure 19

$236 \times 309 \mathrm{~mm}(300 \times 300 \mathrm{DPI})$ 


\section{Tables}

Table 1. Soil description and estimated in-situ stresses

\begin{tabular}{|c|c|c|c|c|c|c|}
\hline \multirow[t]{2}{*}{ Soil } & \multirow{2}{*}{$\begin{array}{l}\text { Age } \\
\text { [Mya] }\end{array}$} & \multicolumn{3}{|c|}{ In-situ stresses } & \multirow[t]{2}{*}{ Micro-structure $^{b}$} & \multirow[t]{2}{*}{ Meso-structure $^{c}$} \\
\hline & & $\mathrm{K}_{0}^{\mathrm{a}}$ & $\begin{array}{c}\mathrm{p}_{0}^{\prime} \\
{[\mathrm{kPa}]}\end{array}$ & $\begin{array}{c}\sigma_{\mathrm{v} 0}^{\prime}-\sigma_{\mathrm{h} 0}^{\prime} \\
{[\mathrm{kPa}]}\end{array}$ & & \\
\hline Oxford clay & $\begin{array}{c}\text { Upper } \\
\text { Jurassic } \\
161-156\end{array}$ & $\begin{array}{c}3.2 \\
(3-7)\end{array}$ & 250 & -223 & $\begin{array}{l}\text { Strong horizontal } \\
\text { orientation of particles } \\
\text { and shells }\end{array}$ & $\begin{array}{l}\text { No significant fissuring but } \\
\text { highly bedded. Horizontal shell } \\
\text { beds. }\end{array}$ \\
\hline $\begin{array}{c}\text { Kimmeridge } \\
\text { clay }\end{array}$ & $\begin{array}{l}\text { Upper } \\
\text { Jurassic } \\
156-151\end{array}$ & $\begin{array}{c}1.8 \\
(1.5-3)\end{array}$ & 186 & -97 & $\begin{array}{l}\text { No strong preferred } \\
\text { orientation due to } \\
\text { presence of larger silt } \\
\text { particles }\end{array}$ & $\begin{array}{l}\text { Close spaced fissuring }(2-5 \mathrm{~cm} \\
\text { spacing) sub-horizontal \& } 40^{\circ} \text { - } \\
60^{\circ} \text { to Vertical }\end{array}$ \\
\hline Gault clay & $\begin{array}{l}\text { Lower } \\
\text { Cretaceous } \\
112-99\end{array}$ & $\begin{array}{c}1.8 \\
(1.5-3)\end{array}$ & 163 & -85 & $\begin{array}{l}\text { No strong preferred } \\
\text { orientation due to } \\
\text { presence of larger micro- } \\
\text { fossils }\end{array}$ & $\begin{array}{l}\text { Close spaced fissuring (spacing } \\
\text { of } 2-5 \mathrm{~cm} \text { ) sub-horizontal and } \\
\text { sub-vertical with frequent zones } \\
\text { of intense fissuring. Presence of } \\
\text { nodules }\end{array}$ \\
\hline $\begin{array}{l}\text { London clay } \\
\text { (Unit B2c) }\end{array}$ & $\begin{array}{c}\text { Eocene } \\
56-49\end{array}$ & $\begin{array}{c}1.8 \\
(1.5-3)\end{array}$ & 323 & -165 & $\begin{array}{l}\text { Moderate particle } \\
\text { orientation }\end{array}$ & $\begin{array}{l}\text { Highly fissured (spacing } \\
\text { typically } 10-20 \mathrm{~cm} \text { ) in sub- } \\
\text { vertical and sub-horizontal } \\
\text { directions }\end{array}$ \\
\hline
\end{tabular}

${ }^{a}$ The estimated chosen value is given on the first line. The range obtained from a variety of methods is indicated in brackets. Note that in the case of Oxford clay, the estimated value could not be reached without over-straining the sample and so a $\mathrm{K}_{0}$ of 1.8 was used ultimately (see Table 3 ).

${ }^{b}$ Wilkinson (2011)

${ }^{c}$ Hosseini-Kamal et al. (2014)

Table 2. Basic index and strength properties

\begin{tabular}{ccccccc}
\hline Soil & $\begin{array}{c}\text { Water content } \\
{[\%]}\end{array}$ & $\begin{array}{c}\text { Plastic Limit } \\
{[\%]}\end{array}$ & $\begin{array}{c}\text { Liquid Limit } \\
{[\%]}\end{array}$ & $\begin{array}{c}\text { Plastic index } \\
{[\%]}\end{array}$ & $\begin{array}{c}\mathrm{S}_{\mathrm{u}} \\
{[\mathrm{kPa}]}\end{array}$ & $\begin{array}{c}\text { Residual } \phi^{\prime} \\
{[\mathrm{Deg}]}\end{array}$ \\
\cline { 1 - 5 } Oxford clay & $24-27$ & $32-35$ & $64-67$ & $30-34$ & $200-300$ & 10 \\
Kimmeridge & $16-21$ & $18-22$ & $46-55$ & $28-33$ & $80-100$ & 7 \\
clay & $28-30$ & $28-31$ & $71-77$ & $40-46$ & $70-90$ & 10 \\
$\begin{array}{c}\text { Gault clay } \\
\text { London clay }\end{array}$ & $23-25$ & $26-27$ & $68-70$ & $41-44$ & $120-170$ & 12 \\
(Unit B2c) & & & & &
\end{tabular}


Table 3. Summary of HCA tests for Oxford clay series

\begin{tabular}{|c|c|c|c|c|c|c|c|c|c|c|}
\hline \multirow{2}{*}{$\begin{array}{c}\text { Test } \\
\text { reference }\end{array}$} & \multirow{2}{*}{$\begin{array}{l}\text { Sample } \\
\text { type }\end{array}$} & \multirow{2}{*}{$\begin{array}{c}\text { Specimen } \\
\text { depth } \\
{[\mathrm{mBGL}]}\end{array}$} & \multirow[t]{2}{*}{ Apparatus } & \multirow{2}{*}{$\begin{array}{l}\text { Type } \\
\text { of } \\
\text { test }^{\mathrm{a}} \\
\end{array}$} & \multicolumn{2}{|c|}{ Initial stresses } & \multirow{2}{*}{$\begin{array}{c}\alpha_{f}^{b} \\
{[\mathrm{Deg}]}\end{array}$} & \multirow{2}{*}{$\begin{array}{l}b \\
{[-]} \\
\end{array}$} & \multirow{2}{*}{$\begin{array}{c}\alpha_{d \sigma} \\
{[\mathrm{Deg}]}\end{array}$} & \multirow{2}{*}{$\begin{array}{c}\mathrm{S}_{\mathrm{u}} \\
\\
{[\mathrm{kPa}]} \\
\end{array}$} \\
\hline & & & & & $\begin{array}{c}\mathrm{p}_{0}^{\prime} \\
{[\mathrm{kPa}]}\end{array}$ & $\begin{array}{c}\sigma_{\mathrm{v} v}^{\prime} \sigma_{\mathrm{h} 0}^{\prime} \\
{[\mathrm{kPa}]}\end{array}$ & & & & \\
\hline OA0005 & block & 10 & ICRCHCA & $\alpha_{\mathrm{d} \sigma}$ & 250 & -130 & 0 & $\begin{array}{l}0 . \\
5\end{array}$ & 0 & 175 \\
\hline OA2305 & block & 10 & ICRCHCA & $\alpha_{\mathrm{d} \sigma}$ & 250 & -130 & 22 & $\begin{array}{l}0 . \\
5\end{array}$ & 15 & 145 \\
\hline OA4505 & block & 10 & ICRCHCA & $\alpha_{\mathrm{d} \sigma}$ & 252 & -125 & 43 & $\begin{array}{l}0 . \\
5\end{array}$ & 30 & 127 \\
\hline OA6705 & block & 10 & ICRCHCA & $\alpha_{\mathrm{d} \sigma}$ & 250 & -130 & 69 & $\begin{array}{l}0 . \\
5\end{array}$ & 57 & 145 \\
\hline OA9005 & block & 10 & ICRCHCA & $\alpha_{\mathrm{d} \sigma}$ & 252 & -125 & 90 & $\begin{array}{l}0 . \\
5\end{array}$ & 90 & 260 \\
\hline OA0005* & block & 10 & ICRCHCA & $\alpha_{\mathrm{d} \sigma}$ & 252 & -125 & 0 & $\begin{array}{l}0 . \\
5\end{array}$ & 0 & 159 \\
\hline OASS & block & 10 & ICRCHCA & SS & 250 & -130 & 57 & - & - & 112 \\
\hline
\end{tabular}

Table 4. Summary of HCA tests for Kimmeridge clay series

\begin{tabular}{|c|c|c|c|c|c|c|c|c|c|c|}
\hline \multirow{2}{*}{$\begin{array}{c}\text { Test } \\
\text { referenc } \\
\mathrm{e}\end{array}$} & \multirow{2}{*}{$\begin{array}{c}\text { Sample } \\
\text { type }\end{array}$} & \multirow{2}{*}{$\begin{array}{c}\text { Specimen } \\
\text { depth } \\
{[\mathrm{mBGL}]}\end{array}$} & \multirow[t]{2}{*}{ Apparatus } & \multirow{2}{*}{$\begin{array}{c}\text { Type } \\
\text { of } \\
\text { test }^{\mathrm{a}}\end{array}$} & \multicolumn{2}{|c|}{ Initial stresses } & \multirow{2}{*}{$\begin{array}{c}\alpha_{f}^{b} \\
{[\mathrm{Deg}]}\end{array}$} & \multirow{2}{*}{$\begin{array}{c}b \\
{[-]}\end{array}$} & \multirow{2}{*}{$\begin{array}{r}\alpha_{d \sigma} \\
{[\mathrm{Deg}]}\end{array}$} & \multirow{2}{*}{$\begin{array}{r}\mathrm{S}_{\mathrm{u}} \\
{[\mathrm{kPa}]}\end{array}$} \\
\hline & & & & & $\begin{array}{c}\mathrm{p}_{0}^{\prime} \\
{[\mathrm{kPa}]}\end{array}$ & $\begin{array}{c}\sigma_{\mathrm{v} 0}^{\prime}-\sigma_{\mathrm{h} 0}^{\prime} \\
{[\mathrm{kPa}]}\end{array}$ & & & & \\
\hline KA0005 & rotary & 11.45 & ICHCA II & $\alpha_{\mathrm{d} \sigma}$ & 186 & -97 & 0 & 0.5 & 0 & 100 \\
\hline KA2305 & rotary & 11.17 & ICHCA II & $\alpha_{\mathrm{d} \sigma}$ & 186 & -97 & 21 & 0.5 & 14 & 97 \\
\hline KA4505 & rotary & 11.52 & ICHCA II & $\alpha_{\mathrm{d} \sigma}$ & 186 & -97 & 40 & 0.5 & 30 & 126 \\
\hline KA6705 & rotary & 11.94 & ICHCA II & $\alpha_{\mathrm{d} \sigma}$ & 186 & -97 & 63 & 0.5 & 55 & 161 \\
\hline KA9005 & rotary & 11.69 & ICHCA II & $\alpha_{\mathrm{d} \sigma}$ & 186 & -97 & 90 & 0.5 & 90 & 175 \\
\hline KASS & rotary & 8.98 & ICRCHCA & SS & 186 & -97 & 53 & - & - & 151 \\
\hline
\end{tabular}

${ }^{\mathrm{a}} \alpha_{\mathrm{d} \sigma}$ refers to shearing at constant direction of principal stress increments $\alpha_{\mathrm{d} \sigma}$; SS to simple shear tests.

${ }^{\mathrm{b}} \alpha_{\mathrm{f}}$ is the $\alpha$ angle at peak $q$. 
Table 5. Summary of HCA tests for Gault clay series

\begin{tabular}{|c|c|c|c|c|c|c|c|c|c|c|}
\hline \multirow{2}{*}{$\begin{array}{c}\text { Test } \\
\text { reference }\end{array}$} & \multirow{2}{*}{$\begin{array}{c}\text { Sample } \\
\text { type }\end{array}$} & \multirow{2}{*}{$\begin{array}{c}\text { Specimen } \\
\text { depth } \\
{[\mathrm{mBGL}]}\end{array}$} & \multirow[t]{2}{*}{ Apparatus } & \multirow{2}{*}{$\begin{array}{c}\text { Type } \\
\text { of } \\
\text { test }^{\mathrm{a}} \\
\end{array}$} & \multicolumn{2}{|c|}{ Initial stresses } & \multirow{2}{*}{$\begin{array}{c}\alpha_{f}^{b} \\
{[\mathrm{Deg}]}\end{array}$} & \multirow{2}{*}{$\begin{array}{c}b \\
b-] \\
\end{array}$} & \multirow{2}{*}{$\begin{array}{r}\alpha_{d \sigma} \\
{[\mathrm{Deg}]}\end{array}$} & \multirow{2}{*}{$\begin{array}{r}\mathrm{S}_{\mathrm{u}} \\
\\
{[\mathrm{kPa}]}\end{array}$} \\
\hline & & & & & $\begin{array}{c}\mathrm{p}_{0}^{\prime} \\
{[\mathrm{kPa}]}\end{array}$ & $\begin{array}{c}\sigma_{\mathrm{v} 0^{-}}^{\prime} \\
\sigma_{\mathrm{h} 0} \\
{[\mathrm{kPa}]}\end{array}$ & & & & \\
\hline GA0005 & rotary & 9.50 & ICRCHCA & $\alpha_{\mathrm{d} \sigma}$ & 163 & -85 & 0 & 0.5 & 0 & 106 \\
\hline GA2305 & rotary & 9.76 & ICRCHCA & $\alpha_{\mathrm{d} \sigma}$ & 163 & -85 & 21 & 0.5 & 15 & 104 \\
\hline GA4505 & rotary & 11.77 & ICRCHCA & $\alpha_{\mathrm{d} \sigma}$ & 163 & -85 & 39 & 0.5 & 28 & 94 \\
\hline GA6705 & rotary & 10.60 & ICRCHCA & $\alpha_{\mathrm{d} \sigma}$ & 163 & -85 & 65 & 0.5 & 55 & 112 \\
\hline GA9005 & rotary & 10.30 & ICRCHCA & $\alpha_{\mathrm{d} \sigma}$ & 163 & -85 & 90 & 0.5 & 90 & 126 \\
\hline GASS & rotary & 10.85 & ICRCHCA & SS & 163 & -85 & 53 & - & & 99 \\
\hline
\end{tabular}

${ }^{\mathrm{a}} \alpha_{\mathrm{d} \sigma}$ refers to shearing at constant direction of principal stress increments $\alpha_{\mathrm{d} \sigma} ;$ SS to simple shear tests.

${ }^{\mathrm{b}} \alpha_{\mathrm{f}}$ is the $\alpha$ angle at peak $q$.

Table 6. Summary of HCA tests for London clay series

\begin{tabular}{|c|c|c|c|c|c|c|c|c|c|c|}
\hline \multirow{2}{*}{$\begin{array}{c}\text { Test } \\
\text { reference }\end{array}$} & \multirow{2}{*}{$\begin{array}{l}\text { Sample } \\
\text { type }\end{array}$} & \multirow{2}{*}{$\begin{array}{c}\text { Specimen } \\
\text { depth } \\
\text { [mBGL] }\end{array}$} & \multirow[t]{2}{*}{ Apparatus } & \multirow{2}{*}{$\begin{array}{l}\text { Type } \\
\text { of } \\
\text { test }^{\mathrm{a}}\end{array}$} & \multicolumn{2}{|c|}{ Initial stresses } & \multirow{2}{*}{$\begin{array}{c}\alpha_{f}^{b} \\
{[\mathrm{Deg}]}\end{array}$} & \multirow{2}{*}{$\begin{array}{c}b \\
{[-]}\end{array}$} & \multirow{2}{*}{$\begin{array}{r}\alpha_{d \sigma} \\
{[\mathrm{Deg}]}\end{array}$} & \multirow{2}{*}{$\begin{array}{r}\mathrm{S}_{\mathrm{u}} \\
\\
{[\mathrm{kPa}]}\end{array}$} \\
\hline & & & & & $\begin{array}{c}\mathrm{p}_{0}^{\prime} \\
{[\mathrm{kPa}} \\
]\end{array}$ & $\begin{array}{c}\sigma_{\mathrm{v} 0}^{\prime}-\sigma_{\mathrm{h} 0}^{\prime} \\
{[\mathrm{kPa}]}\end{array}$ & & & & \\
\hline LA0005 & block & $10.5^{\mathrm{a}}$ & ICRCHCA & $\alpha_{\mathrm{d} \sigma}$ & 323 & -165 & 0 & 0.5 & 0 & 159 \\
\hline LA2305 & block & 10.5 & ICRCHCA & $\alpha_{\mathrm{d} \sigma}$ & 323 & -165 & 23 & 0.5 & 15 & 152 \\
\hline LA4505 & block & 10.5 & ICRCHCA & $\alpha_{\mathrm{d} \sigma}$ & 323 & -165 & 48 & 0.5 & 30 & 121 \\
\hline LA6705 & block & 10.5 & ICRCHCA & $\alpha_{\mathrm{d} \sigma}$ & 323 & -165 & 67 & 0.5 & 55 & 191 \\
\hline LA9005 & block & 10.5 & ICRCHCA & $\alpha_{\mathrm{d} \sigma}$ & 323 & -165 & 90 & 0.5 & 90 & 242 \\
\hline LASS & block & 10.5 & ICRCHCA & SS & 323 & -165 & 53 & - & - & 122 \\
\hline
\end{tabular}

${ }^{a}$ The calculated in-situ stresses take into account an extra $5.8 \mathrm{~m}$ layer of gravel that was removed about 70 years prior to sampling (see Nishimura et al. 2007).

${ }^{\mathrm{b}} \alpha_{\mathrm{d} \sigma}$ refers to shearing at constant direction of principal stress increments $\alpha_{\mathrm{d} \sigma}$; SS to simple shear tests.

${ }^{c} \alpha_{\mathrm{f}}$ is the $\alpha$ angle at peak $q$.

Table 7. Range for suction measurements, slope dq/dp' in triaxial compression tests, and the resulting estimated $\mathrm{K}_{0}$ in for each soil.

\begin{tabular}{cccc}
\hline Soil & $\begin{array}{c}\text { Suction range } \\
{[\mathrm{kPa}]}\end{array}$ & $\begin{array}{c}\text { Slope dq/dp' } \\
{[-]}\end{array}$ & $\begin{array}{c}\mathrm{K}_{0} \text { range } \\
{[\mathrm{kPa}]}\end{array}$ \\
\hline Oxford & $200-220$ & $-2.15--2.75$ & $3.9-6.5$ \\
Kimmeridge & $136-190$ & $-2.4--2.75$ & $1.4-3.2$ \\
Gault & $95-135$ & $-2.5--2.75$ & $0.6-2$ \\
London $^{\mathrm{a}}$ & $200-260$ & Infinity (Isotropic) & $1.8-2$ \\
\hline${ }^{\mathrm{a}}$ Gasparre (2005) - suction measurements on thin-wall samples.
\end{tabular}


Table 8. Estimated strain resolution based on the resolution of the instrumentation

\begin{tabular}{cccc}
\hline Strain & $\begin{array}{c}\text { ICRCHCA } \\
\text { Resolution } \\
{[\%] \times 10^{-3}}\end{array}$ & $\begin{array}{c}\text { ICHCA II (Global) } \\
\text { Resolution } \\
{[\%] \times 10^{-3}}\end{array}$ & $\begin{array}{c}\text { ICHCA II (Local) } \\
\text { Resolution } \\
{[\%] \times 10^{-3}}\end{array}$ \\
\hline$\varepsilon_{z}$ & 0.22 & 0.24 & 0.88 \\
$\varepsilon_{r}$ & 0.34 & 0.27 & 0.15 \\
$\varepsilon_{\theta}$ & 0.25 & 0.32 & 0.25 \\
$\gamma_{z}$ & 0.19 & 3.5 & 0.19 \\
$\varepsilon_{v}$ & 0.16 & 0.2 & 1.38 \\
\hline
\end{tabular}

Table 9. Initial stiffnesses calculated by linear regression up to $0.005 \%$ strain - average for each soil.

\begin{tabular}{ccccccc}
\hline Soil & $p_{0}^{\prime}$ & $\mathrm{E}_{\mathrm{v} 0}^{\mathrm{U}}$ & $\mathrm{E}_{\mathrm{h} 0}^{\mathrm{U}}$ & $\mathrm{G}_{\mathrm{vh} 0}$ & $\mathrm{E}_{\mathrm{h} 0}{ }^{\mathrm{U}} / \mathrm{E}_{\mathrm{v} 0}{ }^{\mathrm{U}}$ \\
{$[\mathrm{kPa}]$} & {$[\mathrm{Mpa}]$} & {$[\mathrm{Mpa}]$} & {$[\mathrm{Mpa}]$} & $\begin{array}{c}3 * \mathrm{G}_{\mathrm{vn} 0} / \mathrm{E}_{\mathrm{v} 0}{ }^{\mathrm{U}} \\
{[-]}\end{array}$ \\
\hline Oxford & 250 & 287 & 655 & 69 & 2.3 & 0.72 \\
Kimmeridge & 186 & 229 & 270 & 56 & 1.2 & 0.73 \\
Gault & 163 & 173 & 377 & 62 & 2.2 & 1.07 \\
London & 323 & 212 & 335 & 71 & 1.6 & 1.00 \\
\hline
\end{tabular}

